\title{
From Electrical Engineering and Computer Science to Fuzzy Languages and the Linguistic Approach of Meaning: The non-technical Episode: 1950-1975
}

\author{
R. Seising
}

\author{
Rudolf Seising \\ European Centre for Soft Computing \\ Edificio Científico-Tecnológico $3 \stackrel{a}{a}$ Planta, \\ C Gonzalo Gutiérrez Quirós S/N \\ Mieres, Asturias, Spain \\ E-mail: rudolf.seising@softcomputing.es
}

\begin{abstract}
:
In this paper we illuminate the first decade of Fuzzy Sets and Systems (FSS) where nobody thought that this theory would be successful in the field of applied sciences and technology. We show that especially Lotfi A. Zadeh, the founder of the theory of FSS, expected that his theory would have a role in the future of computer systems as well as humanities and social sciences. When Mamdani and Assilian picked up the idea of FSS and particularly Fuzzy Algorithms to establish a first Fuzzy Control system for a small steam engine, this was the Kick-off for the "Fuzzy-Boom" in Japan and later in the whole world and Zadeh's primary intention trailed away for decades. Just in the new millennium a new movement for Fuzzy Sets in Social Sciences and Humanities was launched and, hopefully, will persist!
\end{abstract}

Keywords: fuzzy T-S model, fuzzy logic systems, nonlinear systems, uncertainties, tracking control.

\section{Introduction}

About half a decade after his seminal papers "Fuzzy Sets" and "Fuzzy Sets and Systems" have appeared in print [1,2], Lotfi A. Zadeh (born 1921), the founder of this mathematical theory, notified that he did not expect the incorporation of fuzzy sets and systems (FSS) into the fields of sciences and engineering. He was then professor and chair of Electrical Engineering (EE) at US Berkeley the name of the department changed in the year 1967 to Electrical Engineering and Computer Science (EECS) - and he wrote: "What we still lack, and lack rather acutely, are methods for dealing with systems which are too complex or too ill-defined to admit of precise analysis. Such systems pervade life sciences, social sciences, philosophy, economics, psychology and many other "soft" fields." [3,4] In the first years after his foundation, the theory of FSS Zadeh was intended to open the field of its applications to humanities and social sciences. Also reading an interview that was printed in the Azerbaijan International, in 1994, we can improve this view: when Zadeh was asked, "How did you think Fuzzy Logic would be used at first?" his retrospective answer was: "In many, many fields. I expected people in the social scienceseconomics, psychology, philosophy, linguistics, politics, sociology, religion and numerous other areas to pick up on it. It's been somewhat of a mystery to me, why even to this day, so few social scientists have discovered how useful it could be."

In section III we refer to some of the papers that Zadeh has recited, written, or published between 1965 and 1975 that consolidate the perspective that the inventor of FSS wished to establish his new mathematical theory to the humanities, arts and social sciences. Then he was very surprised when Fuzzy Logic (FL) was first in the 1970s "embraced by engineers" and later 
in that decennium FSS has been successful "used in industrial process controls and in 'smart' consumer products such as hand-held camcorders that cancel out jittering and microwaves that cook your food perfectly at the touch of a single button." He said: "I didn't expect it to play out this way back in 1965." [5]

We prefix in the following section II the pre-history of FSS and FL to show that this great change in science in the 20th century originates from two developments in its first half: computers and system theory, and Zadeh was involved in both of them. Therefore, in section II.1 we focus his work concerning "thinking machines" and in section II. 2 we consider his progress in generalizing system theory ${ }^{1}$.

\section{The Age of Computers and System Theory}

\subsection{From "Thinking Machines" and System Theory to "Making Computers think like people"}

After the Second World War, computers next to the atomic bomb, the most famous technical product of war research became popular as "electronic brains" or "thinking machines". This "era of computers" started already with the analogue MIT Differential Analyzer of Vannevar Bush (1890-1974) but the digital machines that have been built during the war, ENIAC (Electronic Numerical Integrator and Computer) and EDVAC (Electronic Discrete Variable Computer), both designed by John Presper Eckert (1919-1995) and John William Mauchly (1907-1980), gave this technological development an eminent push.

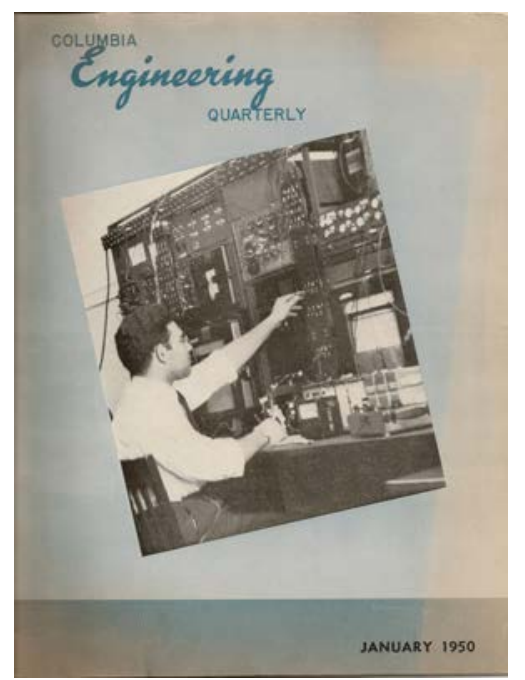

Figure 1: Title page of the Columbia Engineering Quarterly, January 1950.

In the spring of 1945 the mathematician John von Neumann (1903-1957) was asked to prepare a report on the logical principles of the EDVAC, since the ENIAC had not had any such description and it had been sorely missed. In this report [7] he adopted the neuron model from a paper of Warren Sturgis McCulloch (1898-1968) and Walter H. Pitts (1924-1959) [8] that explained the brain and nervous system to a logical computer and drew the inverse conclusion. The similarity between neurons and electric switching elements was apparently so clear to him that he did not thoroughly question it. When the British mathematician Alan Mathison Turing (1912-1954) published in 1950 his famous article "Computing Machinery and Intelligence" [9] in

\footnotetext{
${ }^{1}$ For details to the genesis of FSS and FL see: [6]
} 
the journal Mind the answer of the following question was very popular and also of philosophical interest: "Can machines think?" Turing proposed the well-known imitation game, now called the "Turing test", to decide whether a computer or a program could think like a human being or not. In those days the young electrical engineer Lotfi Aliasker Zadeh (Fig. 2, left side) was interested in these new computing machines. In 1949 he had obtained a position at Columbia University in New York as an instructor responsible for teaching the theories of circuits and electromagnetism but after this year, when he had received his $\mathrm{Ph}$. D., he turned his attention to the problems of computers. Inspired by a lecture of Claude E. Shannon (1916-2001) in New York in 1946, two years before his "Mathematical Theory of Communication" would be published [10], and also by Norbert Wiener's (1894-1964) famous book Cybernetics [11], Zadeh served as a moderator at a debate on digital computers at Columbia University between Shannon, Edmund C. Berkeley (1909-1988), the author of the book Giant Brains or Machines That Think published in 1949 [12], and Francis J. Murray (1911-1996), a mathematician and consultant to IBM.
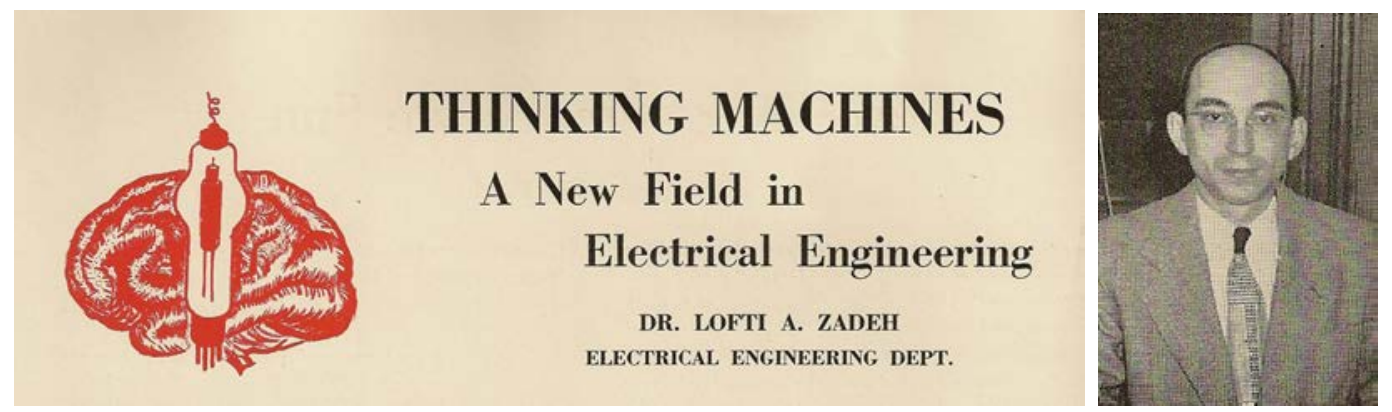

Figure 2: Left: Illustration accompanying Zadeh's article [13]; right: Lotfi A. Zadeh in the 1940s, picture in [13], p. 13.

Then, in 1950, still unaware of Turing's philosophical article, Zadeh wrote the paper "Thinking Machines A New Field in Electrical Engineering" (Fig. 2, right side), which appeared in the student journal The Columbia Engineering Quarterly (Fig. 1) in New York City in 1950 [13]. Here, Zadeh put up for discussion the questions "How will 'electronic brains' or 'thinking machines' affect our way of living?" and "What is the role played by electrical engineers in the design of these devices?" ( [13], p. 12.] He was looking for "the principles and organization of machines which behave like a human brain. Such machines were then variously referred to as "thinking machines", "electronic brains", "thinking robots", and similar names. He mentioned that the "same names are frequently ascribed to devices which are not "thinking machines" in the sense used in this article", therefore he separated as follows: "The distinguishing characteristic of thinking machines is the ability to make logical decisions and to follow these, if necessary, by executive action." ( [13], p. 12.) He stated: "More generally, it can be said, that a thinking machine is a device which arrives at a certain decision or answer through the process of evaluation and selection." With this definition he decided that the MIT Differential Analyzer was not a thinking machine, but both then built large-scale digital computers, UNIVAC (Universal Automatic Computer) and BINAC (Binary Automatic Computer), were thinking machines because they both were able to make non-trivial decisions. ( [13], p. 13.) Zadeh explained in this article "how a thinking machine works" (Fig. 3) and he claimed, "the box labelled Decision Maker is the most important part of the thinking machine".

Zadeh illustrated his argumentation by peering forward into the year 1965, which was then 15 years in the future. Three years earlier, in this version of the future, the administration at Columbia University had decided, for reasons of economy and efficiency, to close the admissions office and install in its place a thinking machine called the "Electronic Admissions Director". The 


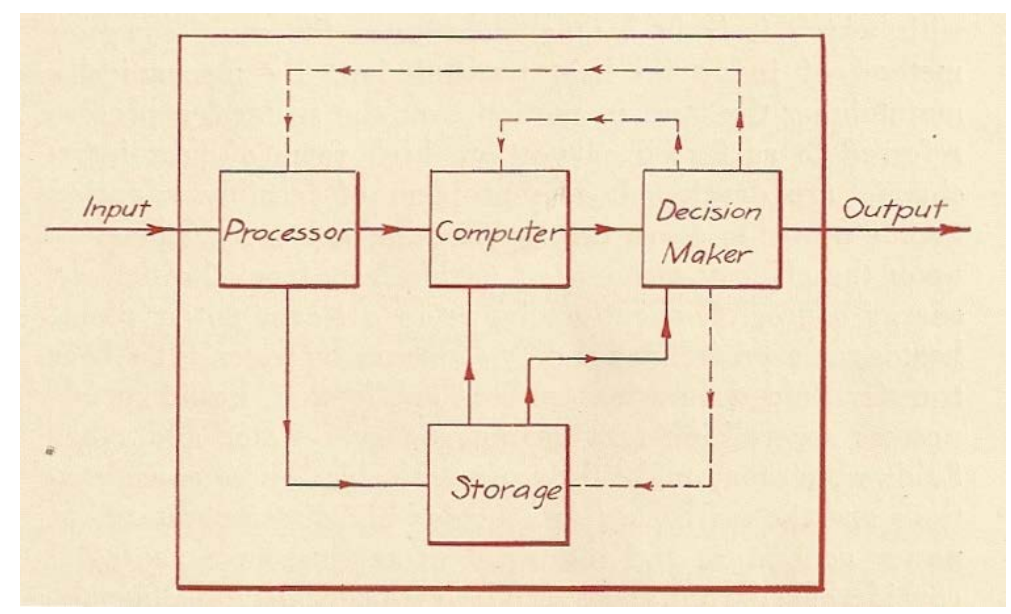

Figure 3: Zadeh's chart for the basic elements of a "Thinking Machine", [13], p. 13.

construction and design of this machine had been entrusted to the electrical engineering department, which completed the installation in 1964. Since then, the "director" has been functioning perfectly and enjoying the unqualified support of the administration, departments and students. This "thinking machine" functions as follows:

1. Human secretaries convert the information from the list of applicants into series of numbers $a_{1}, a_{2}, a_{3}, \ldots, a_{n}$; each number represents a characteristic, e. g. $a_{1}$ could stand for the applicant's IQ, $a_{2}$ for personal character, and so on.

2. The lists coded thusly are provided to the processor, which processes them and then relays some of the data to the computer and another part of the data to storage. On the basis of applicant data as well as university data, the computer calculates the probabilities of various events, such as the probability that a student will fail after the first five years. This information and the saved data are sent to the decision maker to come to final decision on whether to accept the applicant. The decision is then made based on directives, such as these two:

- Accept if the probability of earning the Bachelor's degree is greater than $60 \%$;

- Reject if the probability that the applicant will not pass the first year of college is greater than $20 \%$.

Zadeh didn't consider the machine sketched out here to be as fanciful as student readers (and surely others, as well) may have thought: Machines such as this could be commonplace in 10 or 20 years and it is already absolutely certain that thinking machines will play an important role in armed conflicts that may arise in the future. ( [13], p. 30) Now, in the year 1950, though, there was still much to be done so that these or similar scenarios of the future could become reality.

"Thinking Machines are essentially electrical devices. But unlike most other electrical devices, they are the brain children of mathematicians and not of electrical engineers. Even at the present time most of the advanced work on Thinking Machines is being done by mathematicians. This situation will last until electrical engineers become more proficient in those fields of mathematics which form the theoretical basis for the design of Thinking Machines. The most important of these fields is that of symbolic logic." ( [13], p. 31). 
The fundamental principles of "thinking machines", Zadeh stressed, were developed by mathematicians, but today, after more than 50 years of Artificial Intelligence (AI) - a research program that was launched in 1959, that spread to many scientific and technological communities throughout the world and that includes a number of successes - we know that AI has lagged behind expectations. AI became a field of research aimed at developing computers and computer programs that act "intelligently" even though no human being controls these systems. AI methods became methods of computing with numbers and finding exact solutions. As well, humans are able to resolve such tasks very well, as Zadeh mentioned very often over the last decades. In conclusion, Zadeh stated that "thinking machines" do not think as humans do.

In the 1960s Zadeh's research topic was System Theory, chapter II.2 is concerned with this development in detail, but in the 1970s, Zadeh connected the two research subjects with each other when he distinguished between mechanic (or inanimate or man-made) systems at one hand and humanistic systems at the other hand. He saw the following state of the art in computer technology: "Unquestionably, computers have proved to be highly effective in dealing with mechanistic systems, that is, with inanimate systems whose behaviour is governed by the laws of mechanics, physics, chemistry and electromagnetism. Unfortunately, the same cannot be said about humanistic systems, which so far at least have proved to be rather impervious to mathematical analysis and computer simulation." He explained that a "humanistic system" is "a system whose behaviour is strongly influenced by human judgement, perception or emotions. Examples of humanistic systems are: economic systems, political systems, legal systems, educational systems, etc. A single individual and his thought processes may also be viewed as a humanistic system." ( [14], p. 200) To summarize, he argued, "that the use of computers has not shed much light on the basic issues arising in philosophy, literature, law, politics, sociology and other human-oriented fields. Nor have computers added significantly to our understanding of human thought processes excepting, perhaps, some examples to the contrary that can be drawn from artificial intelligence and related fields." ( [14], p. 200).

Computers have been very successful in mechanic systems but they could not be that successful humanistic systems in the field of non-exact sciences. Zadeh argued that this is the case because of his so-called Principle of Incompatibility that he established in 1973 for the concepts of exactness and complexity: "The closer one looks at a 'real world' problem, the fuzzier becomes its solution." $[15]^{3}$ With this principle there is a difference between system analysis and simulations that are based on precise number computing at one hand and analysis and simulations of humanistic systems at the other hand. Zadeh conjectured that precise quantitative analysis of the behaviour of humanistic systems are not meaningful for "real-world societal, political, economic, and other types of problems which involve humans either as individuals or in groups." ( [15], p. 28).

From the mid-1980s he focused on "Making Computers Think like People". [16] For this purpose, the machine's ability to "compute with numbers" was supplemented by an additional ability that was similar to human thinking. The "remarkable human capability [of humans] to perform a wide variety of physical and mental tasks without any measurements and any computations" inspired him and he has given everyday examples of such tasks in many papers: parking a car, playing golf, deciphering sloppy handwriting, and summarizing a story. Underlying this, is the human ability to reason with perceptions "perceptions of time, distance, speed, force, direction, shape, intent, likelihood, truth and other attributes of physical and mental objects." ( [17], p. 903).

\footnotetext{
${ }^{3}$ More explicitly: "Stated informally, the essence of this principle is, that as the complexity of a system increases, our ability to make precise and yet significant statements about its behaviour diminishes until a threshold is reached beyond which precision and significance (or relevance) become almost mutually exclusive characteristics." $[15]$
} 


\section{Making computers think like people}

The term 'fuzzy thinking' is pejorative when applied to humans, but fuzzy logic is an asset to machines in applications from expert systems to process control

Figure 4: Headline of L. A. Zadehs 1984-paper [16].

\subsection{From Circuit Theory to Fuzzy Systems Theory}

Let's go back to the 1950's! Also in the Columbia Engineering Quarterly Zadeh published in 1954 the article "System Theory" [18] where, he characterized systems as a "black boxes" with inputs $u_{1}, \ldots, u_{m}$ and outputs $\nu_{1}, \ldots, \nu_{n},(m, n \in N$ (Fig. 5), and in the case that these inputs and outputs are describable as time dependent functions then the dynamic behaviour of the system can be studied mathematically, and the input-output-relationship of the system is

$$
\left(\nu_{1}, \ldots, \nu_{n}\right)=f\left(u_{1}, \ldots, u_{m}\right)
$$

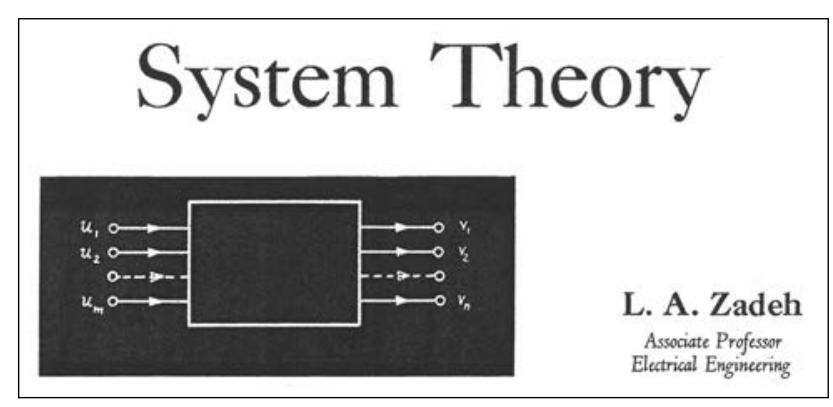

Figure 5: Headline of L. A. Zadehs 1954-paper showing a system with inputs and outputs, [18], p. 16.

Of course, in Zadeh's later system theoretic papers a more sophisticated treatment of these interrelationships is visible: "Suppose that a system $A$ is specified as a given combination of $N$ component systems $A_{1}, \ldots, A_{N}$, each of which is defined as a specified set of input-output pairs. How can one deduce from the knowledge of these sets of input-output pairs and the way in which the components $A$ (that is $A_{1}, \ldots, A_{N}$ ) are combined the set of input-output pairs which constitutes $A$ ? This question presents one of the central problems of system theory." ( [18], p. $18)$.

In the early 1950s, system theory was a rising scientific discipline "to the study of systems per se, regardless of their physical structure". Engineers in that time were, in general, inadequately trained to think in abstract terms, but nevertheless, Zadeh believed that it was only a matter of time before system theory would attain acceptance. It turns out that he was right: Eight years later, when he wrote the article "From Circuit Theory to System Theory" [19] for the anniversary edition of the Proceedings of the IRE appeared in May 1962 to mark the 50th year of the Institute of Radio Engineers (IRE), he could describe problems and applications of system theory and its relations to network theory, control theory, and information theory. Furthermore, he pointed out "that the same abstract "systems" notions are operating in various guises in many unrelated fields of science is a relatively recent development. It has been brought about, largely within the past two decades, by the great progress in our understanding of the behaviour 
of both inanimate and animate systems-progress which resulted on the one hand from a vast expansion in the scientific and technological activities directed toward the development of highly complex systems for such purposes as automatic control, pattern recognition, data-processing, communication, and machine computation, and, on the other hand, by attempts at quantitative analyses of the extremely complex animate and man-machine systems which are encountered in biology, neurophysiology, econometrics, operations research and other fields" ( [19], p. 856f.).

After 1958, when Zadeh became a professor of electrical engineering at the University of California, Berkeley he published papers on system theory and two well known books with colleagues at his new department: He authored Linear System Theory together with Charles A. Desoer (1926-2010) in 1963 [20] and he edited the volume System Theory with Elijah Polak (born 1931) [21]. His own contribution in the latter book has the title "The Concept of State in System Theory" [22]. This concept of state was Zadeh's "new view" in System Theory that he presented also in April 1963, when he participated in the Second Systems Symposium at the Case Institute of Technology in Cleveland, Ohio. 17 speakers and more than 200 participants, systems scientists in terms of the general systems theory and cybernetics but also technical system scientists tried to discuss relations between technical and nontechnical system science.

The proceedings, published by Mihaljo D. Mesarović (born 1928), were entitled Views on General Systems Theory [23] and here Zadeh placed a general notion of state in system theory [24]. His starting points were the fields of dynamical systems and of automata. To present a simple example, Zadeh referred to an important subject in the history of computer science that is named after Alan Turing: the Turing machine. "In From Circuit Theory to System Theory" [19] he came from this idea: "Roughly speaking, a Turing machine is a discrete time $(t=0,1,2, \ldots)$ system with a finite number of states or internal configurations, which is subjected to an input having the form of a sequence of symbols (drawn from a finite alphabet) printed on a tape which can move in both directions along its length. The output of the machine at time $t$ is an instruction to print a particular symbol in the square scanned by the machine at time $t$ and to move in one or the other direction by one square. A key feature of the machine is that the output at time $t+1$ and the state at time $t+1$ are determined by the state and the input at time $t$ ( [19], p. 858). If $s_{t}, u_{t}$, and $y_{t}$ denote state, input, and output of the Turing machine at time $t$, respectively, and if $f$ and $g$ are functions on pairs of $s_{t}$ and $u_{t}$, then the machine-operation is characterized by the following set of state equations:

$$
\begin{gathered}
s_{t+1}=f\left(s_{t}, u_{t}\right), t=0,1,2, \ldots \\
y_{t}=g\left(s_{t}, u_{t}\right)
\end{gathered}
$$

If the system is a differential system instead of a discrete-state system, state, input, and output of the system are represented by vectors $s(t), y(t)$, and $u(t)$, respectively. With $\dot{s}(t)=$ $d / d t s(t)$, state equations assume the forms

$$
\begin{aligned}
& \dot{s}(t)=f(s(t), u(t)) \\
& y(t)=g(s(t), u(t))
\end{aligned}
$$

Some mathematicians and control theorists in the Soviet Union in the 1940s and 1950s, as the Russian mathematician Lew Semjonowitsch Pontrjagin (1908-1988), used these state equations more early than western scientists, and Lotfi Zadeh has been familiar with the scientific progress in the Soviet Union. He referred to the fact that "in the United States, the introduction of the notion of state and related techniques into the theory of optimization of linear as well as nonlinear 


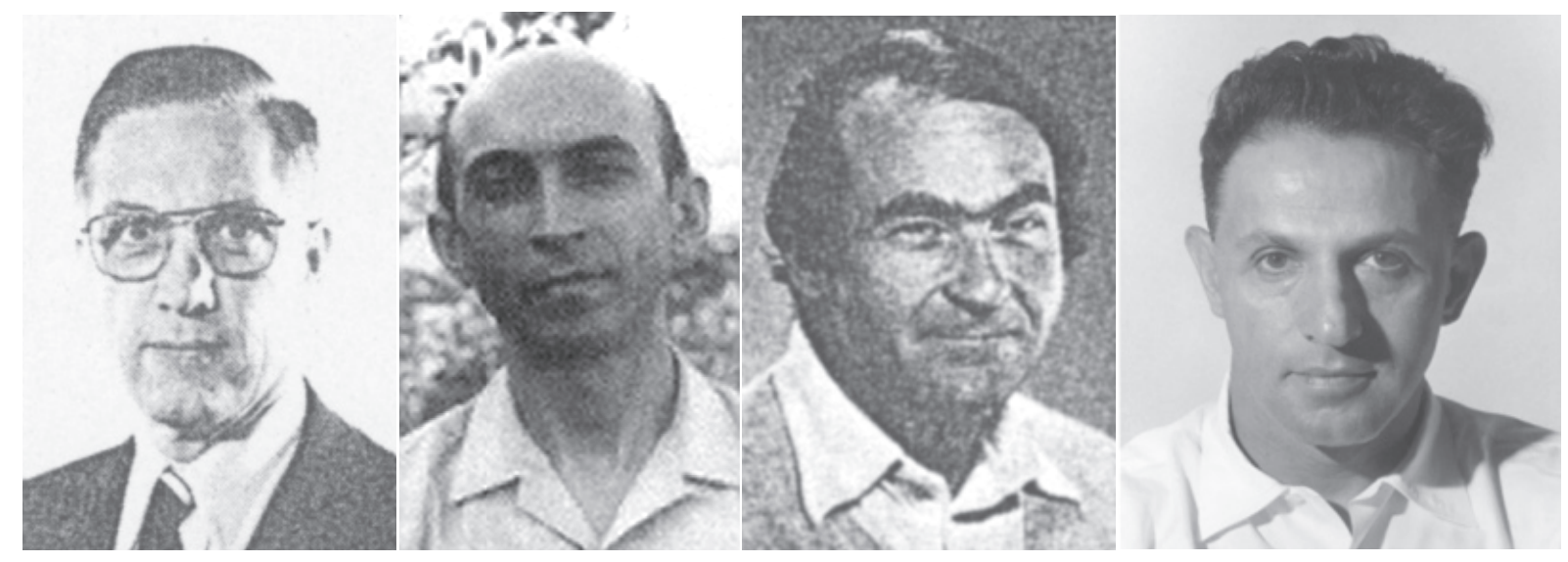

Figure 6: Left to right: Charles A. Desoer, Lotfi A. Zadeh, Elijah Polak, Richard E. Bellman
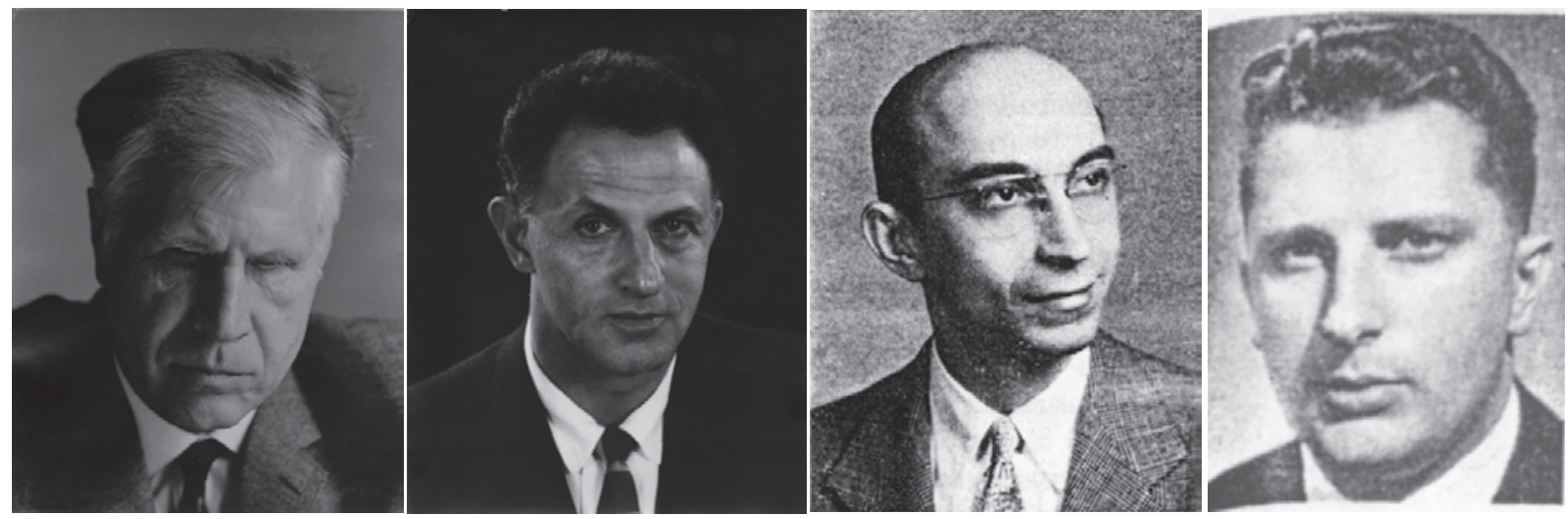

Figure 7: Left to right: Lew S. Pontrjagin, Richard E. Bellman, Lotfi A. Zadeh, Robert Kalaba.

systems is due primarily to Richard Ernest Bellman (1920-1984), whose invention of dynamic programming has contributed by far the most powerful tool since the inception of the variational calculus to the solution of a whole gamut of maximization and minimization problems." ( [19], p. 858.).

Bellman and Zadeh have been very close friends and in the summer of 1964 they planned on doing some research together at RAND in Santa Monica where Bellman was employed, but before that time, Zadeh was supposed to give a talk on pattern recognition in the Wright-Patterson Air Force Base, Dayton, Ohio.

During this travel he started thinking about pattern recognition problems and grades of membership of an object to be an element of a class as he returned to mind almost 50 years later: "While I was serving as Chair, I continued to do a lot of thinking about basic issues in systems analysis, especially the issue of unsharpness of class boundaries. In July 1964, I was attending a conference in New York and was staying at the home of my parents. They were away. I had a dinner engagement but it had to be canceled. I was alone in the apartment. My thoughts turned to the unsharpness of class boundaries. It was at that point that the simple concept of a fuzzy set occurred to me. It did not take me long to put my thoughts together and write a paper on the subject. This was the genesis of fuzzy set theory." ( [26], p.7). ${ }^{4}$

When Zadeh met Bellman in Santa Monica, they both discussed a new theory of membership grades and sets with fuzzy borders. Then, Zadeh wrote a paper on these "fuzzy sets" and some

\footnotetext{
${ }^{4} \mathrm{~A}$ more detailled presentation of the history of the theory of FSS and FL is give in the author's book [6]
} 




Figure 8: Left: title page of the Rand-memorandum [27]; right: title page of the article [28].

INFORMATION AND CONTROL 8, 338-353 (1965)
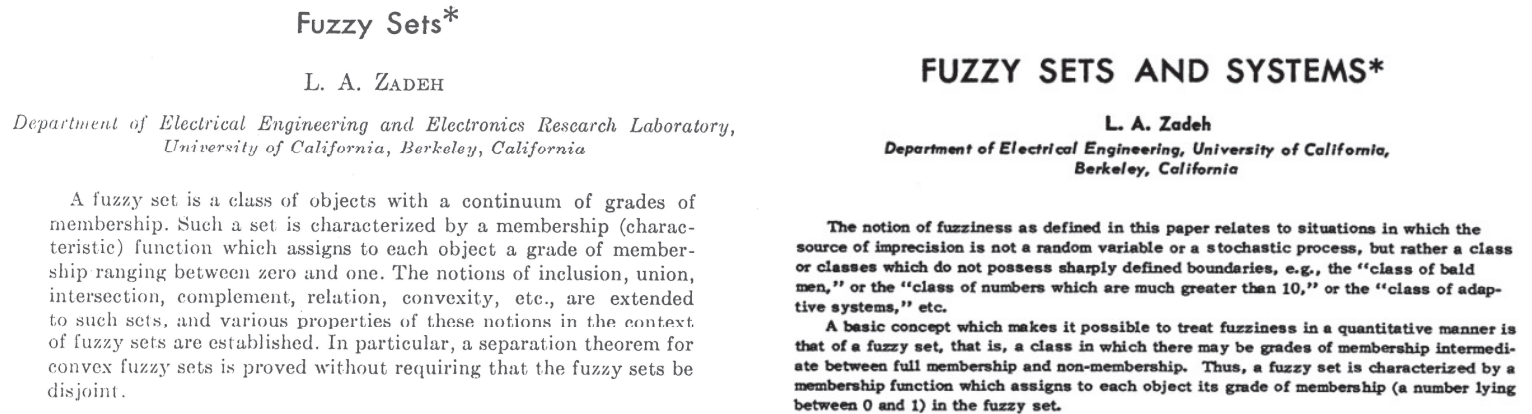

Figure 9: Headline of Zadeh's article "Fuzzy Sets" [29] of his proceedings contribution, emanated from his talk "A New View on System Theory" [30].

pattern recognition problems. This paper appeared as a RAND-Corporation memorandum in October 1964 by the authors Bellman, his collaborator Robert Kalaba (1926-2004), and Zadeh [27]. The paper, written by Lotfi Zadeh, contains the first definitions of the theory of fuzzy sets in a scientific text. Two years later the same paper appeared under the same title and authorship in the International Journal for Applied Mathematics and Applications [28].

Zadeh submitted his first article "Fuzzy Sets" to the editors of Information and Control in November 1964 and it appeared in this journal in June 1965 [27]. Many years later he wrote: "I knew that the word "fuzzy" would make the theory controversial. Knowing how the real world functions, I submitted my paper to Information and Control because I was a member of the Editorial Board. There was just one review - which was very lukewarm. I believe that my paper would have been rejected if I were not on the Editorial Board. Today, with over 26,000 Google Scholar citations, "Fuzzy sets" is by far the highest cited paper in Information and Control." ( [27], p.7).

Zadeh's third paper on fuzzy sets came out in the proceedings of the Symposium on System 
Theory (April 20-22, 1965) at the Polytechnic Institute in Brooklyn, where Zadeh gave a talk with the title "A New View on System Theory"7. This view dealt with the concepts of fuzzy sets and in this talk Zadeh defined "fuzzy systems": A system $S$ is a fuzzy system if (input) $u(t)$, output $y(t)$, or state $x(t)$ of $S$ or any combination of them ranges over fuzzy sets. ( [30], p. 33) He explained that "these concepts relate to situations in which the source of imprecision is not a random variable or a stochastic process but rather a class or classes which do not possess sharply defined boundaries." ( [30], p. 29) He noticed, "Such classes are not classes or sets in the usual sense of these terms, since they do not dichotomize all objects into those that belong to the class and those that do not". may be a continuous infinity of grades of membership, with the grade of membership of an object $x$ in a fuzzy set $A$ represented by a number $\mu A(x)$ in the interval $[0,1]$ ". Zadeh maintained that these new concepts provide a "convenient way of defining abstraction - a process which plays a basic role in human thinking and communication." ( [30], p. 29).

Also 17 years later, in his contribution to the 2 nd volume of Kluwer's series "Frontiers in System Research", titled Systems Methodology in Social Science Research: Recent Developments, Zadeh wrote: "The systems theory of the future - the systems theory that will be applicable to the analysis of humanistic systems - is certain to be quite different in spirit as well as in substance from systems theory as we know it today. I will take the liberty of referring to it as fuzzy systems theory because I believe that its distinguishing characteristics will be a conceptual framework for dealing with a key aspect of humanistic systems - namely the pervasive fuzziness of almost all phenomena that are associated with their external as well as internal behavior" [25]. He concluded this paper as follows: "Fuzzy systems theory is not yet an existing theory. What we have at present are merely parts of its foundations. Nevertheless, even at this very early stage of its development, fuzzy systems theory casts some light on the process of approximate reasoning in human decision making, planning, and control. Furthermore, in the years ahead, it is likely to develop into an effective body of concepts and techniques for the analysis of large-scale humanistic as well as mechanistic systems." ( [25], p. 39) More than a decade later, in 1994 he presented perception-based system modeling: "A system, $S$, is assumed to be associated with temporal sequences of input $X_{1}, X_{2}, \ldots$; output $Y_{1}, Y_{2}, \ldots$; and states $S_{1}, S_{2}, \ldots S_{2}$ is defined by state-transition function $f$ with $S_{t+1}=f\left(S_{t}, X_{t}\right)$, and output function $g$ with $Y_{t}=g\left(S_{t}, X_{t}\right)$, for $t=0,1,2, \ldots$ In perception-based system modelling, inputs, outputs and states are assumed to be perceptions, as state-transition function, $f$, and output function, g." ( [32], p. 77.).

This view on future artificial perception-based systems (Fig. 9) - CW-systems and therefore systems to reasoning with perceptions - is the goal of CTP. This view is closely linked by regarding the human brain as a fundamentally fuzzy system. Only in very few situations do people reason in binary terms, as machines classically do. This human characteristic is reflected in all natural languages, in which very few terms are absolute. The use of language is dependent on specific situations and is very seldom $100 \%$ certain. For example, the word "thin" cannot be defined in terms of numbers and there is no measurement at which this term suddenly stops being applicable. Human thinking, language and reasoning can thus indeed be called fuzzy. The theory of fuzzy sets has created a logical system far closer to the functionality of the human mind than any previous logical system. ${ }^{9}$

Fuzzy Sets and Systems and Fuzzy Logic enable them to express uncertainty regarding mea-

\footnotetext{
${ }^{7}$ In the Proceedings of this symposium there is a shortened manuscript version of the talk with the heading Fuzzy Sets and Systems [30]

${ }^{8}[29]$, p. 29. Zadeh used quotation marks to indicate the difference between usual classes or sets and his new (fuzzy) sets.

${ }^{9}$ For more details concerning the history of the theory of Fuzzy Sets and Systems and also its technical applications see [6].
} 


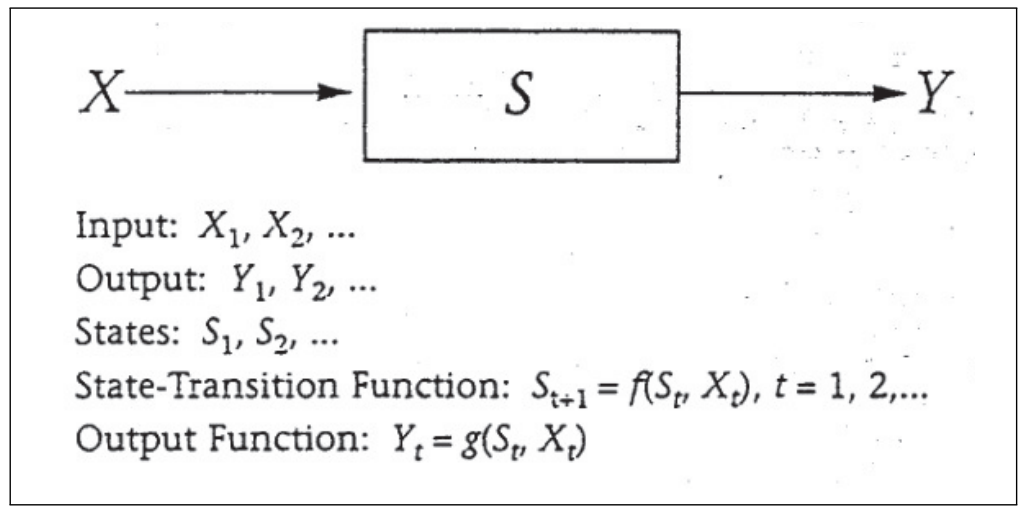

Figure 10: Perception-based system modelling, [32].

surements, diagnostics, evaluations, etc. In theory, this should put the methods of communication used by machines and human beings on levels that are much closer to each other.

\section{From Fuzzy Logic to Fuzzy Languages}

\subsection{Fuzzy Logic}

To understand what happened from coming from Fuzzy Sets and Systems to the idea of the CTP we have go once again back to the roots. In the 1960s Zadeh looked for applying fuzzy sets in linguistics. This idea led to interdisciplinary scientific exchange on the campus of the University of California at Berkeley between him and the mathematician Joseph Goguen (19412006) - who was a Ph. D. student of his, his Berkeley-colleague Hans-Joachim Bremermann (1926-1996), who was then in the mathematics department on the one hand and between the psychologist Eleanor Rosch (Heider) (born 1938) and the Berkeley-linguist George Lakoff (born 1941) on the other. Zadeh had served as first reviewer for Goguens's Ph.D. thesis "Categories of Fuzzy Sets" [33] and Bremermann served as the second. In this work, Goguen generalized the fuzzy sets to so-called "L-sets" [34]. An $L$-set is a function that maps the fuzzy set carrier $X$ into a partially ordered set $L: A: X \rightarrow L$. The partially ordered set $L$ Goguen called the "truth set" of $A$. The elements of $L$ can thus be interpreted as "truth values"; in this respect, Goguen then also referred to a "Logic of Inexact Concepts" [35].

Since Zadeh's earlier definition had established this truth set as the unit interval, Fuzzy Set Theory was very soon associated with multi-valued logics, and also Lotfi Zadeh mentioned this in later papers, e.g.: "It should be noted that a membership function may be regarded as a predicate in a multivalued logic in which the truth values range over $\{0,1] . "$ ( [30], p. 131, fn. 2 ). Goguen's generalization of the set of values to a set $L$ for which the only condition was to be partially ordered cleared up these misunderstandings. Goguen's work was laid out in terms of logical algebra and category theory, and his proof of a representation theorem for $L$-sets within category theory justified Fuzzy Set Theory as an expansion of set theory.

\subsection{Fuzziness for Biology and Computer Science}

Also in 1969 Zadeh gave a talk on "Biological Applications of the Theory of Fuzzy Sets and Systems" [36] where he proposed his new mathematical theory to the life scientists, when he wrote: "The great complexity of biological systems may well prove to be an insuperable block to the achievement of a significant measure of success in the application of conventional mathematical techniques to the analysis of systems." [36] "By 'conventional mathematical techniques' 

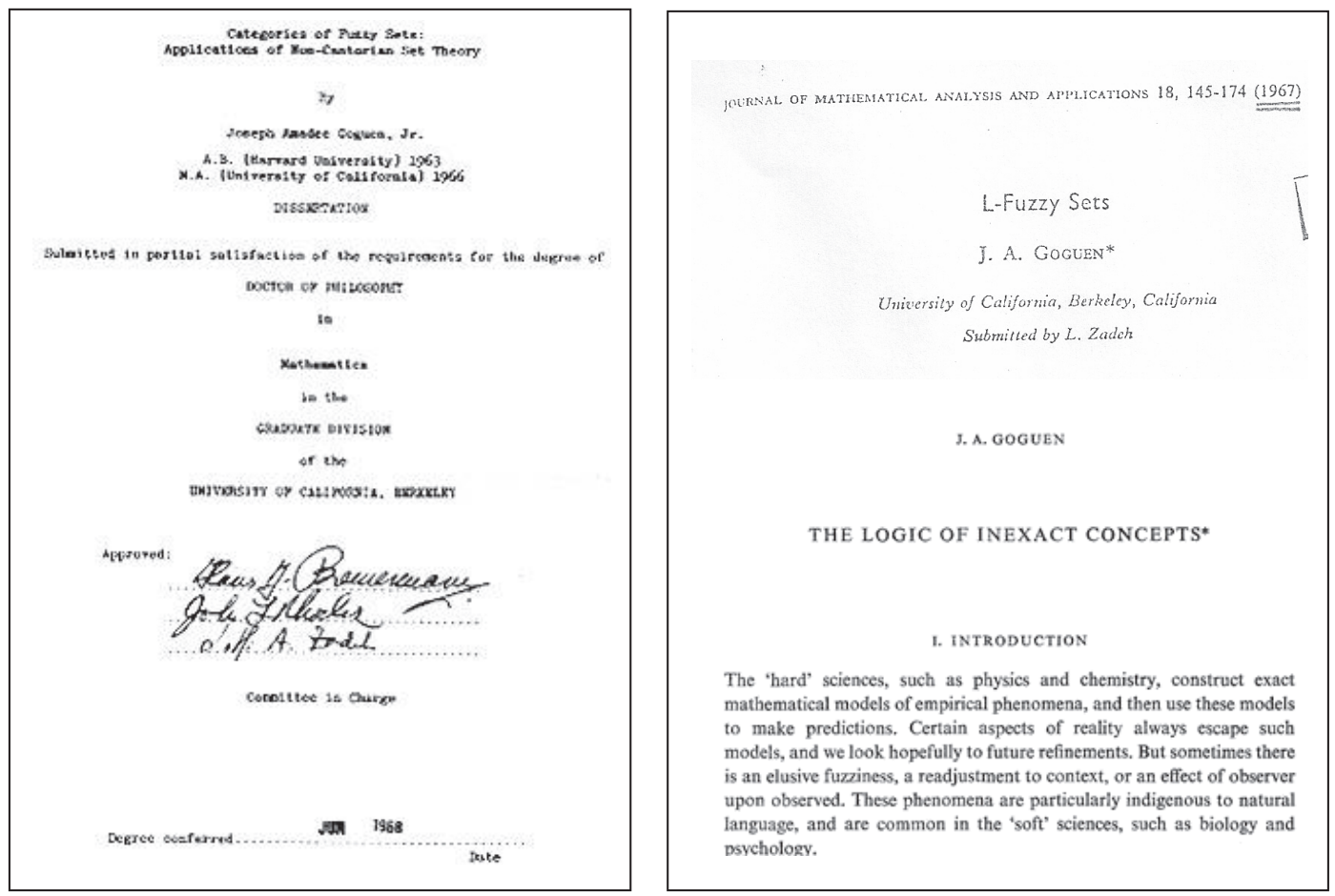

Figure 11: Left: Title page of Goguen's PhD thesis [33], right: Title pages of Goguen's articles [34] and [35].
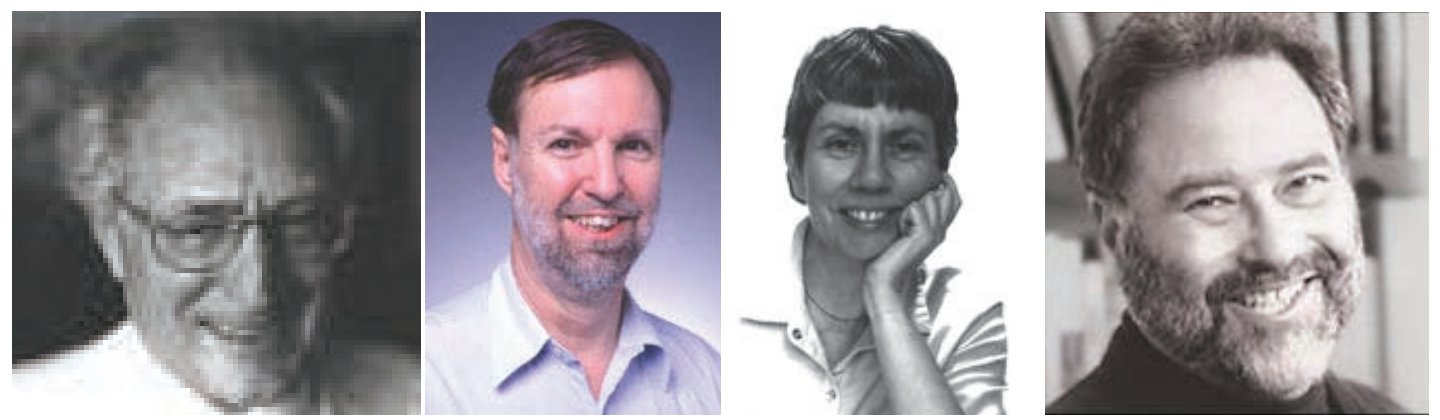

Figure 12: Left to right: Hans J. Bremermann, Joseph Goguen, Eleanor Rosch, George Lakoff.

in this statement, we mean mathematical approaches for which we expect that precise answers to well-chosen precise questions concerning a biological system should have a high degree of relevance to its observed behavior. Indeed, the complexity of biological systems may force us to alter in radical ways our traditional approaches to the analysis of such systems. Thus, we may have to accept as unavoidable a substantial degree of fuzziness in the description of the behavior of biological systems as well as in their characterization." [36] In the same year he wrote more generally: "What we still lack, and lack rather acutely, are methods for dealing with systems which are too complex or too ill-defined to admit of precise analysis. Such systems pervade life sciences, social sciences, philosophy, economics, psychology and many other "soft" fields." [37,38].

Since that time, Zadeh is inspired by the "remarkable human capability to perform a wide variety of physical and mental tasks without any measurements and any computations", e. g. parking a car, playing golf, deciphering sloppy handwriting, and summarizing a story.

However, in 1970, 20 years after later then his first paper on "Thinking machines" [13], Zadeh 
Biological Application of the Theory of Fuzzy Sets and Systems

\section{Toward a Theory of Fuzzy Systems}

\author{
L. A. Zadeh
}

University of California, Berkeley, California
L. A. Zadeh

Figure 13: Headlines of Zadeh's 1969 papers [36] and [38].

\title{
Theoretical Research and Informatic
}

\author{
Man and Computer. Proc. int. Conf., Bordeaux 1970, pp. 130-165 \\ (Karger, Basel 1972) \\ Fuzzy Languages and their Relation to \\ Human and Machine Intelligence ${ }^{1}$ \\ L.A. ZADEH \\ Department of Electrical Engineering and Computer Sciences \\ and the Electronics Research Laboratory, University of California, Berkeley, Calif.
}

Figure 14: Headlines of Zadeh's 1970 paper "Fuzzy Languages and their Relation to Human and Machine Intelligence" [31].

was aware of Turing's philosophical article [9] when he presented his paper "Fuzzy Languages and their Relations to Human and Machine Intelligence" at the conference "Man and Computer" in Bordeaux, France: "The question of whether or not machines can think has been the subject of many discussions and debates during the past two decades." 11 He continued: "As computers become more powerful and thus more influential in human affairs, the philosophical aspects of this question become increasingly overshadowed by the practical need to develop an operational understanding of the limitations of the machine judgment and decision making ability. Can computers be relied upon to match people, decide on promotions and dismissals, make medical diagnoses, prescribe treatments, act as teachers, formulate business, political and military strategies, and, more generally, perform intellectual tasks of high complexity which in the past required expert human judgment? Clearly, this is already a pressing issue which is certain to grow in importance in the years ahead." ( [31], p. 130).

He called it a paradox that the human brain is always solving problems by manipulating "fuzzy concepts" and "multidimensional fuzzy sensory inputs" whereas "the computing power of the most powerful, the most sophisticated digital computer in existence is not able to do this". Therefore, he stated that "in many instances, the solution to a problem need not be exact, so that a considerable measure of fuzziness in its formulation and results may be tolerable. The human brain is designed to take advantage of this tolerance for imprecision whereas a digital computer, with its need for precise data and instructions, is not." ( [31], p. 132) One year later these arguments should culminate in Zadeh's Principle of Incompatibility that we mentioned already in section II.1, whereas here he intended to push his theory of fuzzy sets to model the imprecise concepts and directives: "Indeed, it may be argued that much, perhaps most, of human thinking and interaction with the outside world involves classes without sharp boundaries in which the

\footnotetext{
${ }^{11}$ Here, Zadeh gave 10 citations, including that of Turing: [40, 9, 7, 41- 47].
} 
transition from membership to non-membership is gradual rather than abrupt." ( [31], p. 131) He stated: "Although present-day computers are not designed to accept fuzzy data or execute fuzzy instructions, they can be programmed to do so indirectly by treating a fuzzy set as a data-type which can be encoded as an array [...]."12

Granted that this is not a fully satisfactory approach to the endowment of a computer with an ability to manipulate fuzzy concepts, it is at least a step in the direction of enhancing the ability of machines to emulate human thought processes. It is quite possible, however, that truly significant advances in artificial intelligence will have to await the development of machines that can reason in fuzzy and non-quantitative terms in much the same manner as a human being." ( [31], p. 132).

In August 1967, the Filipino electrical engineer William Go Wee (born 1937) at Purdue University in Indiana had submitted his dissertation "On Generalizations of Adaptive Algorithms and Application of the Fuzzy Sets Concept to Pattern Classification" that he had written under King Sun $\mathrm{Fu}^{13}$, one of the pioneers in the field of pattern recognition (see Fig. 15). Wee had applied the fuzzy sets to iterative learning procedures for pattern classification and had defined a finite automaton based on Zadeh's concept of the fuzzy relation as a model for nonsupervised learning systems: "The decision maker operates deterministically. The learning section is a fuzzy automaton. The performance evaluator serves as an unreliable "teacher" who tries to teach the "student" to make right decisions." ( [50], p. 101).

The fuzzy automaton representing the learning section implemented a "nonsupervised" learning fuzzy algorithm and converged monotonously. Wee showed that this fuzzy algorithm could not only be used in the area of pattern classification but could also be translated to control and regulation problems. He also demonstrated that the fuzzy automaton he had defined contained the concepts of deterministic and non-deterministic automata as special cases: "Based on the concept of fuzzy relation defined by Zadeh, a class of fuzzy automata is formulated similar to that of Mealy's definition. A fuzzy automaton behaves in a deterministic fashion. However, it has many properties similar to that of a probabilistic automaton." ( [50], p. 88) Working with his doctoral advisor, Wee presented his findings in the article "A Formulation of Fuzzy Automata and its Applications as a Model of Learning Systems" [51].

At the end of the same year the Chinese student Chin-Liang Chang completed his dissertation "Fuzzy Sets and Pattern Recognition" that was an advancement of Zadeh's thoughts on the separation problem in pattern recognition. This was the first $\mathrm{Ph} \mathrm{D}$ dissertation on Fuzzy Sets that was supervised by Lotfi Zadeh ${ }^{14}$ (see Fig. 1). Chang had also had contact with Professor King Sun Fu to whom he expresses gratitude for the conversations they shared. [52].

Two years later, in "Towards a Theory of Fuzzy Systems" that was first printed as a report in 1969 [37,38], Zadeh's goal was a theory for all systems - including those that were too complex or poorly defined to be accessible to a precise analysis. Alongside the systems of the "soft" fields, the "non-soft" fields were replete with systems that were only "unsharply" defined, namely "when the complexity of a system rules out the possibility of analyzing it by conventional mathematical means, whether with or without the computers". ( [38], p. 469f) As he would also do in the same year in Bordeaux [38], Zadeh was already pointing out here the usefulness of fuzzy sets in computer science: In describing their fields of application, he enumerated the problems that would be solved by future computers. Alongside pattern recognition, these included traffic control systems, machine translation, information processing, neuronal networks and games like chess and checkers. We had lost sight of the fact that the class of non-trivial problems for which one

\footnotetext{
${ }^{12}$ Here, Zadeh referenced to the early article (1970) on "Fuzzy programs" by his student Shi Kuo Chang [48].

${ }^{13}$ King Sun Fu (1930-1985) was a professor at the Purdue School of Electrical Engineering, West Lafayette, Indiana (1960-1985) and was the founding president of the International Association for Pattern Recognition.

${ }^{14} \mathrm{~A}$ listing of dissertations supervised by Zadeh: http://www.eecs.berkeley.edu/Pubs/Dissertations/Faculty/zadeh.html.
} 




Figure 15: Attendees at the 1st NAFIPS Meeting in Logan, Utah, 1982. King Sun Fu is in the middle of the first row. (Left to right) 1. row: Paul P. Wang, Ebrahim Mamdani, King Sun Fu, James T. P. Yao, L. Saitta. 2. row: Marc Roubens, Philippe Smets, Janet Efstathiou, Richard Tong, Ron R. Yager. Top row: Piero Bonissone, Jim Bezdek, Enrique H. Ruspini, Elie Sanchez.

could find a precise solution algorithm was very limited, he wrote. Most real problems were much too complex and thus either completely unsolvable algorithmically or - if they could be solved in principle - not arithmetically feasible. In chess, for instance, there was in principle an optimal playing strategy for each stage of the game; in reality, however, no computer was capable of sifting through the entire tree of decisions for all of the possible moves with forward and backward repetitions in order to then decide what move would be the best in each phase of the game. The set of good strategies for playing chess had fuzzy limits similar to the set of tall men - these were fuzzy sets. By far the most systems that remained to be solved were fuzzy systems, and in a footnote Zadeh remarks that the automata proposed by Wee and his supervisor Eugene Santos ${ }^{15}$ were also considered examples of fuzzy systems. ( [38], p. 471, fn. 1).

To make fuzziness a part of system theory, Zadeh presented in 1968 "fuzzy algorithms". With that, he had fuzzified the central concept of computer sciences. "The concept in question will be called a fuzzy algorithm because it may be viewed as a generalization, through the process of fuzzification, of the conventional (nonfuzzy) conception of an algorithm." ( [53], p. 94).

Algorithms depend upon precision. An algorithm must be completely unambiguous and errorfree in order to result in a solution. The path to a solution amounts to a series of commands which must be executed in succession. Algorithms formulated mathematically or in a programming language are based on set theory. Each constant and variable is precisely defined, every function and procedure has a definition set and a value set. Each command builds upon them. Successfully running a series of commands requires that each result (output) of the execution of a command lies in the definition range of the following command, that it is, in other words, an element of the input set for the series. Not even the smallest inaccuracies may occur when defining these

\footnotetext{
${ }^{15}$ Eugene S. Santos studied at the Mapua Institute of Technology in Manila until 1963 and afterward at Ohio State University in Columbus, where he earned the Ph.D. in 1965. In 1974, he became a professor in the department of computer sciences and information systems at Youngstown State University in Youngstown, Ohio.
} 


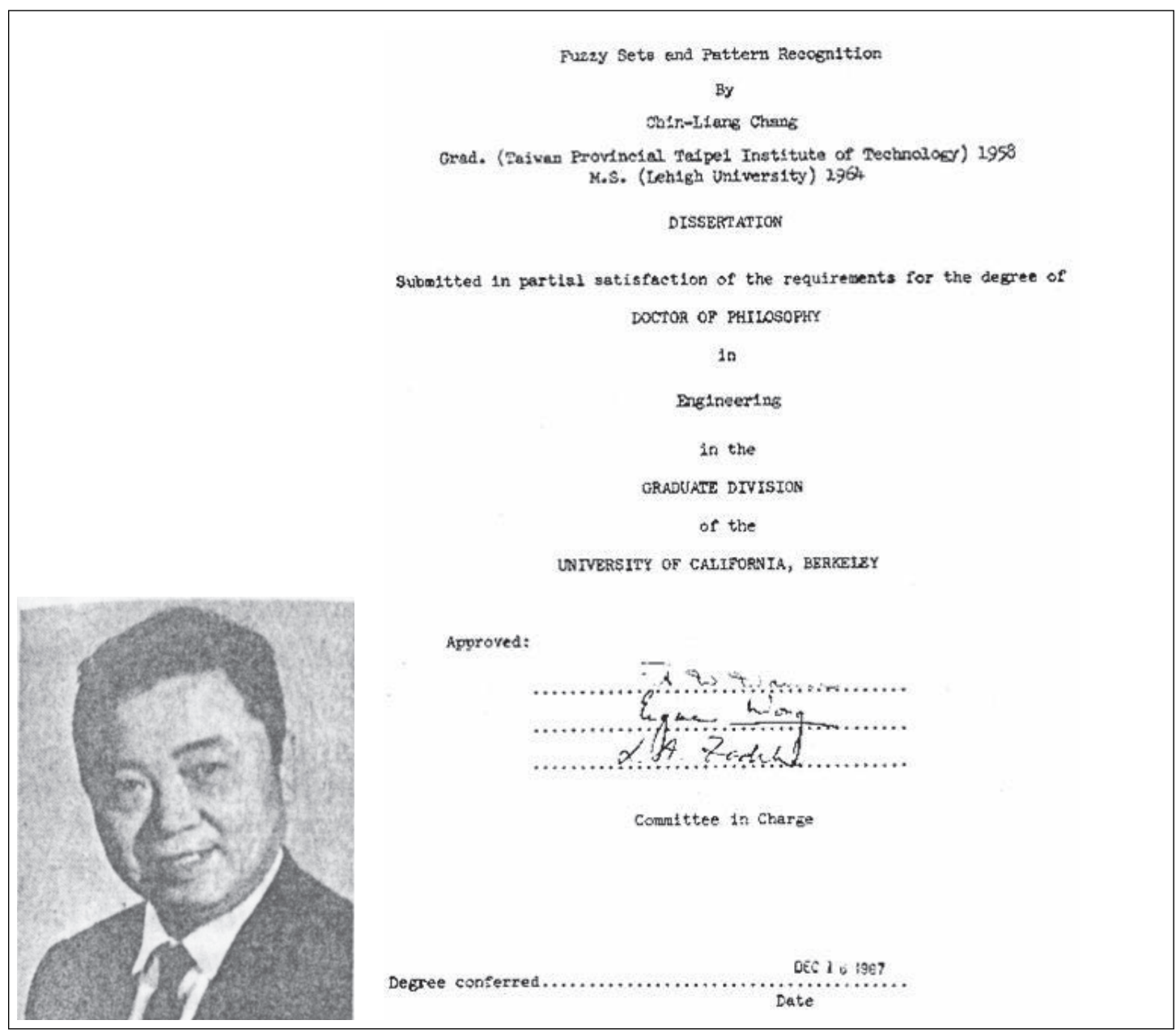

Figure 16: Left: Chin-Liang Chang; right: Title page of Chang's PhD thesis [52].

coordinated definition and value ranges.

After 1965, when Zadeh had fuzzified input, output and state in system theory and had thus founded a theory of fuzzy systems [30], it was obvious to him how to go about fuzzifying algorithms. The commands needed to be fuzzified and so, of course, did their relations! "I began to see that in real life situations people think certain things. They thought like algorithms but not precisely defined algorithms." [53].

Inspired by this idea, he wrote the article "Fuzzy Algorithms" for Information and Control in 1968 which uncharacteristically contained neither theorems nor proofs. Many years later he said that "it is not really a mathematical paper. And the reason why it appeared there is because, again, I was on the editorial board. So it could be published quickly. And I do say it's not a mathematical paper but the idea. But then other people who were mathematicians have developed that and added more mathematical and so forth. So, my function was not that of coming up with very precise. It's just an idea. That's little bit like a composer who just hums something, a sort of orchestrazing ..." [54]. In this article he wrote: "Essentially, its purpose is to introduce a basic concept which, though fuzzy rather than precise in nature, may eventually prove to be of use in a wide variety of problems relating to information processing, control, pattern recognition, system identification, artificial intelligence and, more generally, decision processes involving incomplete or uncertain data. The concept in question will be called fuzzy algorithm because it may be viewed as a generalization, through the process of fuzzification, of 
the conventional (nonfuzzy) conception of an algorithm". ( [53], p. 94).

To illustrate, fuzzy algorithms may contain fuzzy instructions such as: (a) "Set $y$ approximately equal to 10 if $x$ is approximately equal to $5, "$ or (b) "If $x$ is large, increase $y$ by several units," or (c) "If $x$ is large, increase $y$ by several units; if $x$ is small, decrease $y$ by several units; otherwise keep $y$ unchanged." The sources of fuzziness in these instructions are fuzzy sets which are identified by their underlined names. ( [53], p. 94f).

All people function according to fuzzy algorithms in their daily life, Zadeh wrote - they use recipes for cooking, consult the instruction manual to fix a TV, follow prescriptions to treat illnesses or heed the appropriate guidance to park a car. Even though activities like this are not normally called algorithms: "For our point of view, however, they may be regarded as very crude forms of fuzzy algorithms". ( [53], p. 95).

In that time Zadeh wrote also a paper with the title "Toward Fuzziness in Computer Systems. Fuzzy Algorithms and Languages" [55]. I found this typeset-script in Zadeh's office without any reference of publication and date and perhaps it did never appear in print. In the survey-like section on Fuzzy Algorithms he wrote in a footnote "More detailed discussions may be found in [38] and [53]". ${ }^{16}$ Therefore this paper was not written before 1969. The next section in this article is titled "Fuzzy Languages". It has also just two pages and a footnote says: "A more detailed discussion of fuzzy languages appears in a forthcoming paper by E. T. Lee and the writer." Because this paper was published in the journal Information Sciences in 1969 the article [55] is not younger. As a consequence the date of text [55] is 1969, too.

However, the association of fuzziness and computers in the title of this paper must have sounded surprisingly in the late 1960s and referring to that Zadeh set in the introduction to this paper: "At first glance, it may appear highly incongruous to mention computers and fuzziness in the same breath, since fuzziness connotes imprecision whereas precision is a major desideratum in computer design." ( [55], p. 9) In the following paragraphs Zadeh justified this with arguing that the future computer systems will have to perform many more complex information processing tasks than that kind of computers that he and his contemporaries in the 1960s knew. He expected that the future computers have to process more and more imprecise information! "Fuzziness, then, is a concomitant of complexity. This implies that as the complexity of a task, or a system for performing that task, exceeds a certain threshold, the system must necessarily become fuzzy in nature. Thus, with the rapid increase in the complexity of the information processing tasks which the computers are called upon to perform, a point is likely to be reached - perhaps within the next decade - when the computers will have to be designed for processing of information in fuzzy form. In fact, it is this capability - a capability which present-day computers do not possess - that distinguishes human intelligence from machine intelligence. Without such capability we cannot build computers that can summarize written text, translate well from one natural language to another, or perform many other tasks that humans can do with ease because of their ability to manipulate fuzzy concepts." ( [55], p. 10) For that purpose, Zadeh pointed out, "intriguing possibilities for computer systems" are offered by fuzzy algorithms and fuzzy languages!

\subsection{Fuzzy Languages}

Zadeh introduced fuzzy algorithms in the following way: "Roughly speaking, a fuzzy algorithm is an ordered set of instruction containing names of fuzzy sets. An example of such an instruction is "If $x$ is large, set $y$ equal to 2. Otherwise, set $y$ equal to 1"." ( [55], p. 13) To execute such fuzzy instructions by computers they have to get an expression in fuzzy programming languages. Consequently the next step for Zadeh was to define fuzzy languages. Beginning the section with this title in [55], he wrote "All languages, whether natural of artificial, tend to evolve and rise

\footnotetext{
${ }^{16}$ However, in Zadeh's paper these articles have different numbers in the References.
} 
in level through the addition of new words to their vocabulary. These new words are, in effect, names for ordered subsets of names in the vocabulary to which they are added." ( [5], p. 16).

Real world phenomena are very complex and rich of members. To characterize or picture these phenomena in terms of our natural languages we use our vocabulary and because this set of words is restricted, Zadeh argued that this process leads to fuzziness: "Consequently, when we are presented with a class of very high cardinality, we tend to group its elements together into subclasses in such a way as to reduce the complexity of the information processing task involved. When a point is reached where the cardinality of the class of subclasses exceeds the information handling capacity of the human brain, the boundaries of the subclasses are forced to become imprecise and fuzziness becomes a manifestation of this imprecision. This is the reason why the limited vocabulary we have for the description of colors makes it necessary that the names of colors such as red, green, bleu [sic.], purple, etc. be, in effect, names of fuzzy rather than non-fuzzy sets. This is why natural languages, which are much higher in level than programming languages, are fuzzy whereas programming languages are not." ( [55], p. 10) Here, Zadeh argued explicitly for programming languages that are - because of missing rigidness and preciseness and because of their fuzziness - more like natural languages. He mentioned the concept of stochastic languages that was published by the Finnish mathematician Paavo Turakainen in Information and Control in the foregoing year [56], being such an approximation to our human languages using randomizations in the productions, but however, he preferred fuzzy productions to achieve a formal fuzzy language. Then, he presented a short sketch of his program to extend non-fuzzy formal languages to fuzzy languages which he published in elaborated form with the co-author Edward T.-Z. Lee in "Note on Fuzzy Languages" [57]. ${ }^{17}$ His definition in these early papers was given in the terminology of the American computer scientists John Edward Hopcroft (born 1939) and Jeffrey David Ullman (born 1942) that was published in the same year [58].
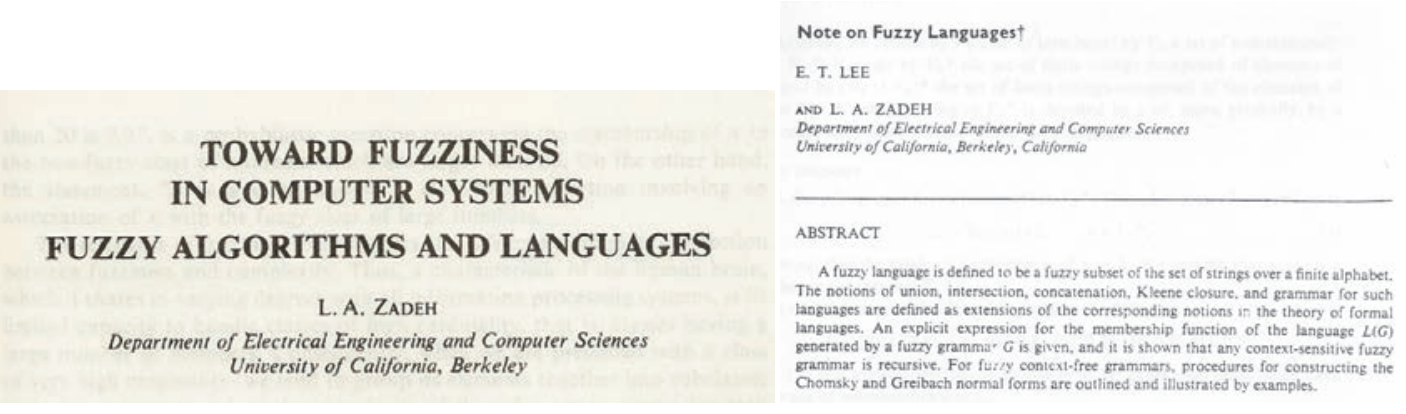

Figure 17: Left: Headline of Zadeh's script from 1969 [55]; right: Headline of the article of Lee and Zadeh [57].

$L$ is a fuzzy language if it is a fuzzy set in the set $V_{T}^{* 18}$ of all finite strings composed of elements of the finite set of terminals $V_{T}$, e.g. $V_{T}=\{a, b, c, \ldots, z\}$. The membership function $\mu_{L}(x): V_{T}^{*} \rightarrow[0,1]$ associates with each finite string $x$, composed of elements in $V_{T}$, its grade of membership in $L$. Here is one of the simple examples that he gave in the early article ( [55], p. 16): "Assume that $V_{T}=\{0,1\}$, and take $L$ to be the fuzzy set $L=$ $\{(0,0.9),(1,0.2),(00,0.8),(01,0.6),(10,0.7),(11,0.3)\}$ with the understanding that all the other strings in $V_{T}^{*}$ do not belong to $L$ (i.e., have grade of membership equal to zero)." ( [55], p. 16).

In general the language $L$ has high cardinality and therefore it is not usual to define it by a listing of its elements but by a finite set of rules for generating them. Thus, in analogy to the

\footnotetext{
${ }^{17}$ Later, E. T. Lee finished his $\mathrm{Ph} \mathrm{D}$ thesis "Fuzzy Languages and Their Relation to Automata" under Zadeh's supervision: [1972]

${ }^{18} V_{T}^{*}$ is called the Kleene closure of $V_{T}$, named after the American mathematician Stephen Kleene (1909-1994).
} 
case of non-fuzzy languages Zadeh defined a fuzzy grammar as "a quadruple $G=\left(V_{N}, V_{T}, P, S\right)$, where $V_{N}$ is a set of variables (non-terminals) disjoint from $V_{T}, P$ is a set of [fuzzy] productions and $\mathrm{S}$ is an element of $V_{N}$. The elements of $V_{N}$ (called [fuzzy] syntactic categories) and $\mathrm{S}$ is an abbreviation for the syntactic category "sentence". The elements of $P$ define conditioned fuzzy sets in $\left(V_{T} \cup V_{N}\right)^{*} . "([55]$, p. 16).

Turning to the 1970's Zadeh worked out the basic framework of his theory of fuzzy sets and fuzzy relations that gave him the opportunity to characterize fuzzy languages broader than before.

\subsection{Fuzzy Relations}

In 1971, Zadeh defined similarity relations and fuzzy orderings [59]. In doing so, he was proceeding from the concept of fuzzy relations as a fuzzification of the relation concept known in conventional set theory that he had already defined in his first text on fuzzy sets [1]: If $X$ and $Y$ are conventional sets and if $X \times Y$ is their Cartesian product, then:

- $L(X)$ is the set of all fuzzy sets in $X$,

- $L(Y)$ is the set of all fuzzy sets in $Y$ and,

- $L(X \times Y)$ is the set of all fuzzy sets in $X \times Y$.

Relations between $X$ and $Y$ are subsets of their Cartesian product $X \times Y$, and the composition $t=q * \mathrm{r}$ of the relation $q \subseteq X \times Y$ with the relation $r \subseteq Y \times Z$ into the new relation $t \subseteq X \times Z$ is given by the following definition: $t=q * r=\{(x, y) \exists y:(x, y) \in q \wedge(y, z) \in r\}$.

Fuzzy relations between sets $X$ and $Y$ are subsets in $L(X \times Y)$. For three conventional sets $X, Y$ and $Z$, the fuzzy relation $Q$ between $X$ and $Y$, and the fuzzy relation $R$ between $Y$ and $Z$ are defined: $Q \in L(X \times Y)$ and $R \in L(Y \times Z)$. The combination of these two fuzzy relations into a new fuzzy relation $T \in L(X \times Z)$ between $X$ and $Z$ can then be combined from the fuzzy relations $Q$ and $R$ into the new fuzzy relation $T \in L(X \times Z)$ when the logical conjunctions are replaced by the corresponding ones of the membership functions.

- The above definition of the composition of conventional relations includes a logical AND $(\wedge)$, which, for the "fuzzification", is replaced by the minimum operator that is applied to the corresponding membership functions. ${ }^{19}$

- The above definition of the composition of conventional relations includes the expression " $\exists$ y" ("there exists a y"). The existing $y \in Y$ is the first or the second or the third ... (and so on); written logically: ( $\vee$ ) sup $y \in Y$. In the "fuzzifications", the logical OR conjunction is replaced by the maximum operator that is applied to the corresponding membership functions. ${ }^{20}$

The fuzzy relation $T=Q * R$ is therefore defined via Zadeh's "combination rule of max-min combination" 21 for the membership functions: $\mu_{T}(x, y)=\max _{y \in Y} \min \left\{\mu_{Q}(x, y) ; \mu_{r}(y, z)\right\}, y \in$ $Y$.

\footnotetext{
${ }^{19}$ Of course, the other proposed fuzzy operators can also be used; in those cases, correspondingly different fuzzy relations are obtained.

${ }^{20}$ In addition to max operator, there are also other conjunction operations for the "fuzzy or" which then lead to other fuzzy relations.

${ }^{21}$ The max-min composition rule is replaced in infinite sets with the sup-min composition rule. However, it is adequate to assume here that all of the sets are finite.
} 
As a generalization of the concept of the equivalence relation Zadeh defined the concept of "similarity", since the similarity relations he defined is reflective, symmetrical and transitive, i.e. for $x, y \in X$ the membership function of $S$ has the following properties:

- Reflexivity: $\mu_{S}(\mathrm{x}, \mathrm{x})=1$;

- Symmetry: $\mu_{S}(\mathrm{x}, \mathrm{y})=\mu_{S}(\mathrm{y}, \mathrm{x})$;

- Transitivity: $\mu_{S}(x, y) \geq \max _{y \in Y} \min \left\{\mu_{S}(x, y) ; \mu_{S}(y, z)\right\}$.

\section{From Fuzzy Logics and Languages to Fuzzy Semantics and back to Fuzzy Logic}

Zadeh's occupation with natural and artificial languages gave rise to his studies in humanities and social sciences, especially on semantics. This intensive work let him to the question "Can the fuzziness of meaning be treated quantitatively, at least in principle?" ( [60], p. 160). His 1971 article "Quantitative Fuzzy Semantics" [60] starts with a hint to this studies: "Few concepts are as basic to human thinking and yet as elusive of precise definition as the concept of "meaning". Innumerable papers and books in the fields of philosophy, psychology, and linguistics have dealt at length with the question of what is the meaning of "meaning" without coming up with any definitive answers." ( [60], p. 159). ${ }^{22}$

INFORMATION SCIENCES

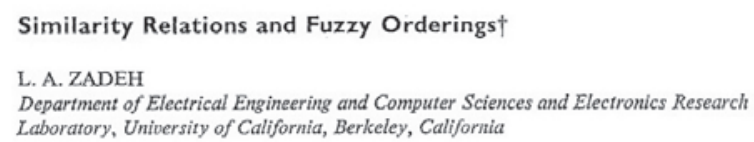

INFORMATIÓN SGIENCES

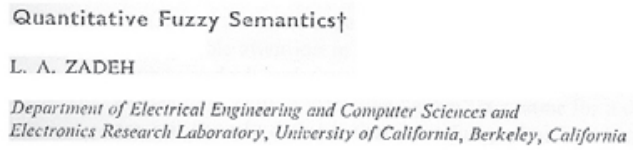

Figure 18: Headlines of Zadeh's articles [59] and [60].

In this paper Zadeh started a new field of research "to point to the possibility of treating the fuzziness of meaning in a quantitative way and suggest a basis for what might be called quantitative fuzzy semantics" combining his results on Fuzzy languages and Fuzzy relations. In the section "Meaning" of this paper he set up the basics: "Consider two spaces: (a) a universe of discourse, $U$, and (b) a set of terms, $T$, which play the roles of names of subsets of $U$. Let the generic elements of $T$ and $U$ be denoted by $x$ and $y$, respectively." Then he started to define the meaning $M(x)$ of a term $x$ as a fuzzy subset of $U$ characterized by a membership function $\mu(y \mid x)$ which is conditioned on $x$. One of his examples was: "Let $U$ be the universe of objects which we can see. Let $T$ be the set of terms white, grey, green, blue, yellow, red, black. Then each of these terms, e.g., red, may be regarded as a name for a fuzzy subset of elements of $U$ which are red in color. Thus, the meaning of red, $M(r e d)$, is a specified fuzzy subset of $U$."

In the following section of this paper, that is named "Language", Zadeh regarded a language $L$ as a "fuzzy correspondence", more explicit, a fuzzy binary relation, from the term set $T=\{x\}$

\footnotetext{
${ }^{22}$ In a footnote he named the books of the philosophers, linguists or cognitive scientists Samuel Abraham (born 1923) and Ferenc Kiefer (born 1931) [61], Yehoshua Bar Hillel (1915-1975) [62], Max Black (1909-1988) [63], Rudolf Carnap (1891-1970) [64], Noam Chomsky (born 1928) [65], Alan Fodor (born 1935) and Jerrold J. Katz (1932-2002) [66], Leonard Linsky (born 1922) [67], Sir John Lyons (born 1932) [68], Shimon Ullman (born 1948) [69], Willard Van Orman Quine (1908-2000) [70]), Sebastian K. Shaumyan (1916-2007) [71], Zellig Harris (1909-1992) [72].
} 
to the universe of discourse $U=\{y\}$ that is characterized by the membership function $\mu_{L}$ : $T \times U \rightarrow[0,1]$.

If a term $x$ of $T$ is given, then the membership function $\mu_{L}(x, y)$ defines a set $M(x) i n U$ with the following membership function: $\mu_{M(x)}(y)=\mu_{L}(x, y)$. Zadeh called the fuzzy set $M(x)$ the meaning of the term $x ; x$ is thus the name of $M(x)$.

With this framework Zadeh continued in his 1972 article [31] that we mentioned already in chapter III. 2 to establish the basic aspects of a theory of fuzzy languages that is "much broader and more general than that of a formal language in its conventional sense." ( [31], p. 134) In the following we quote his definitions of the concepts fuzzy language, structured fuzzy language and meaning:

Definition 1: A fuzzy language $L$ is a quadruple $L=(U, T, E, N)$, in which $U$ is a non-fuzzy universe of discourse; $T$ (called the term set) is a fuzzy set of terms which serve as names of fuzzy subsets of $U ; E$ (called an embedding set for $T$ ) is a collection of symbols and their combinations from which the terms are drawn, i.e., $T$ is a fuzzy subset of $E$; and $N$ is a fuzzy relation from $E$ (or more specifically, the support of $T$ ) to $U$ which will be referred to as a naming relation. ${ }^{23}$

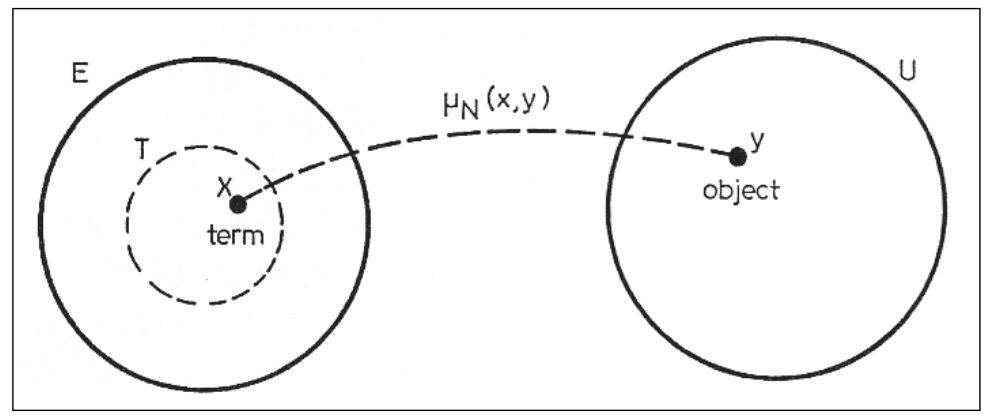

Figure 19: The components of a fuzzy language: $U=$ universe of discourse; $T=$ term set; $E=$ embedding set for $T ; N=$ naming relation from $E$ to $U ; x=$ term; $y=$ object in $U$; $\mu_{N}(x, y)=$ strenght of the relation between $x$ and $y ; \mu_{T}(x)=$ grade of membership of $x$ in $T$.( [31], p.136)

In the case that $U$ and $T$ are infinite large sets, there is no table of membership values for $\mu_{T}(x)$ and $\mu_{N}(x, y)$ and therefore the values of these membership functions have to be computed. To this end, universe of discourse $U$ and term set $T$ have to be endowed with a structure and therefore Zadeh defined the concept of a structured fuzzy language.

Definition 2: A structured fuzzy language $L$ is a quadruple $L=(U, S T, E, S N)$, in which $U$ is a universe of discourse; $E$ is an embedding set for term set $T) S_{T}$ is a set of rules, called syntactic rules of $L$, which collectively provide an algorithm for computing the membership function, $\mu_{T}$, of the term set $T$; and $S_{N}$ is a set of rules, called the semantic rules of $L$, which collectively provide an algorithm for computing the membership function, $\mu_{N}$, of the fuzzy naming relation $N$. The collection of syntactic and semantic rules of $L$ constitute, respectively, the syntax and semantics of $L$.

To define the concept of meaning, Zadeh characterized the membership function $\mu_{N}: \operatorname{supp}(T) \times$ $U \rightarrow[0,1]$ representing the strength of the relation between a term $x$ in $T$ and an object $y$ in $U$.

However, analogously as in the case of systems and fuzzy systems (see chapter II.2) he clarified: "A language, whether structured or unstructured, will be said to be fuzzy if [term set] $T$ or [naming relation] $N$ or both are fuzzy. Consequently, an non-fuzzy language is one in which both $T$ and $N$ are non-fuzzy. In particular, a non-fuzzy structured language is a language with both non-fuzzy syntax and non-fuzzy semantics." [31], p. 138).

\footnotetext{
${ }^{23}$ The support of a fuzzy subset $A$ of $X$ is a non-fuzzy subset $\operatorname{supp}(A)$ defined by $\operatorname{supp}(A)=\left\{x \mid \mu_{A}(x)>0\right\}$.
} 
With these definitions it is clear that natural languages have fuzzy syntax and fuzzy semantics whereas programming languages, as they were usual in the early 1970s, were non-fuzzy structured languages. The membership functions $\mu_{T}$ and $\mu_{N}$ for term set and naming relation, respectively, were two-valued and the compiler used the rules to compute these values 0 or 1 . This means that the compiler decides deterministically by using the syntactic rules whether a string $x$ is a term in $T$ or not and it also determines by using the semantic rules whether a term $x$ hits an object $y$ or not. On the other hand we have natural languages, e.g. English, and it is possible that we use sentences that are not completely correct but also not completely incorrect. These sentences have a degree of grammaticality between 0 and 1 . Of course, at least native speakers use with high frequency correct sentences. "In most cases, however, the degree of grammatically of a sentence is either zero or one, so that the set of terms in a natural language has a fairly sharply defined boundary between grammatical and ungrammatical sentences", Zadeh wrote ( [31], p. 138). ${ }^{24}$

Much more fuzziness we find in semantics of natural languages: Zadeh gave the example "if the universe of discourse is identified with the set of ages from 1 to 100, then the atomic terms young and old do not correspond to sharply defined subsets of $U$. The same applies to composite terms such as not very young, not very young and not very old, etc. In effect, most of the terms in a natural language correspond to fuzzy rather than non-fuzzy subsets of the universe of discourse." ( [31], p. 139).

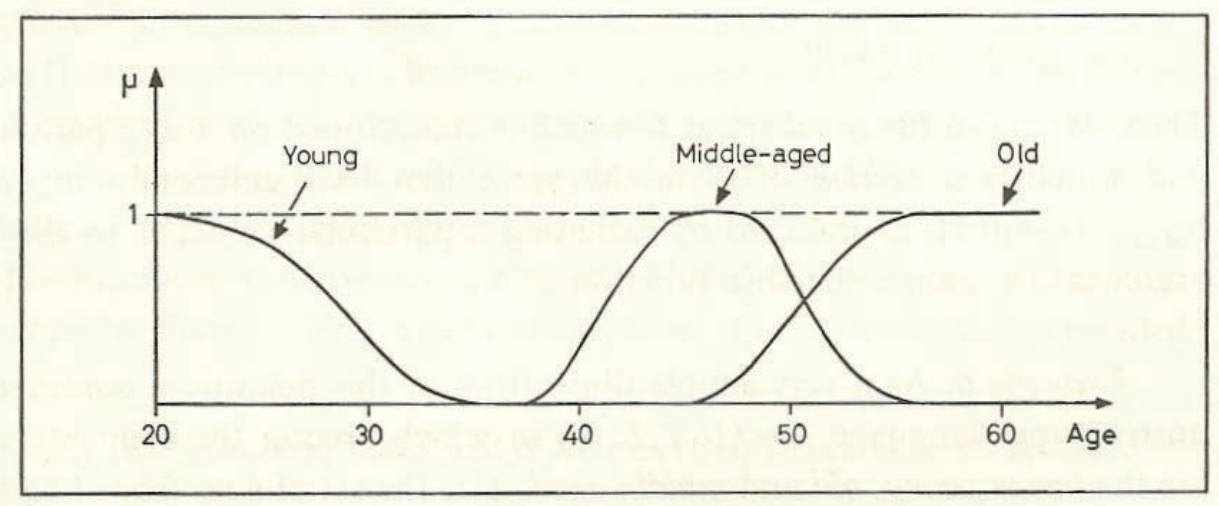

Figure 20: Membership functions of the fuzzy sets $M($ young), $M($ middle - aged) and $M($ old $)$. ( [31], p. 140)

Zadeh now identified these fuzzy subsets of the universe of discourse that correspond to terms in natural languages with its "meaning":

Definition 3: The meaning of a term $x$ in $T$ is a fuzzy subset $M(x)$ of $U$ in which the grade of membership of an element $y$ of $U$ is given by $\mu_{M(x)}(y)=\mu_{N}(x, y)$.

Thus, $M(x)$ is a fuzzy subset of $U$ which is conditioned on $x$ as a parameter and which is a section of $N$ in the sense that its membership function, $\mu_{M(x)}: U \rightarrow[0,1]$, is obtained by assigning a particular value, $x$, to the first argument in the membership function of $N$.

Zadeh concluded this paper mentioning that "the theory of fuzzy languages is in an embryonic stage" but he expressed his hope that basing on this framework better models for natural

\footnotetext{
${ }^{24}$ However, Zadeh mentioned that this observation "that natural languages are generally characterized by slightly fuzzy syntax and rather fuzzy semantics does not necessarily hold true when $T$ is associated with an infinite rather than finite alphabet. Thus, when the terms of a language have the form of sounds, pictures, handwritten characters, etc., the fuzziness of its syntax may be quite pronounced. For example, the class of handwritten characters (or sounds) which correspond to a single letter, say $R$, is rather fuzzy, and this is even more true of concatenation of handwritten characters (or sounds)." [31], p. 139)
} 
languages will be developed than the models of the "restricted framework of the classical theory of formal languages." ( [31], p. 163).

Later in the 1970s he published important papers summarizing and developing the concepts we presented above: in 1973 "Outline of a new approach to the analysis of complex systems and decision processes" [73] appeared in the IEEE Transaction on Systems, Man, and Cybernetics, in 1975 the three-part article "The concept of a Lingustic Variable and its Application to Approximate Reasoning" $[14,74,75]^{25}$ appeared in the journal Information Sciences, in the same year Zadeh published "Fuzzy Logic and Approximate Reasoning" in the philosophical journal Synthese [76] and in 1978 Zadeh published "PRUF - a meaning representation language for natural languages" in the International Journal of Man-Machine Studies [77]. ${ }^{26}$

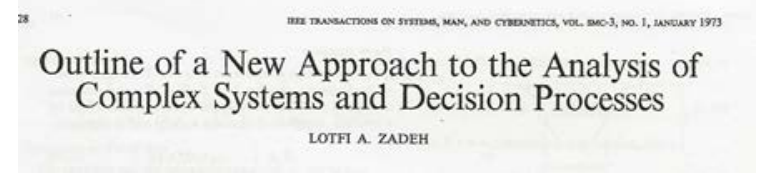

INFORMATION SCIENCES 8. 199-249(1975)

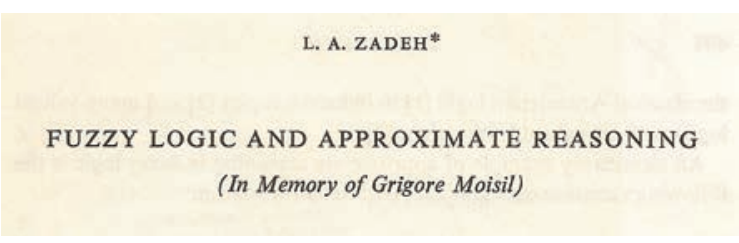

(In Memory of Grigore Moisil)

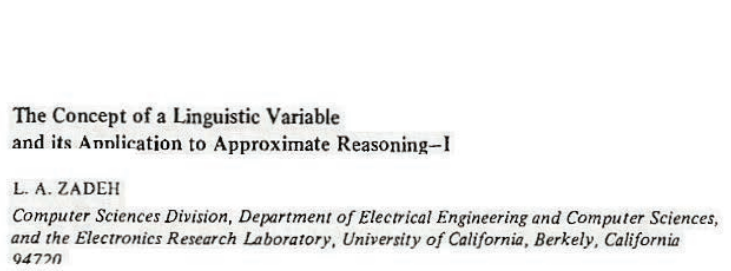

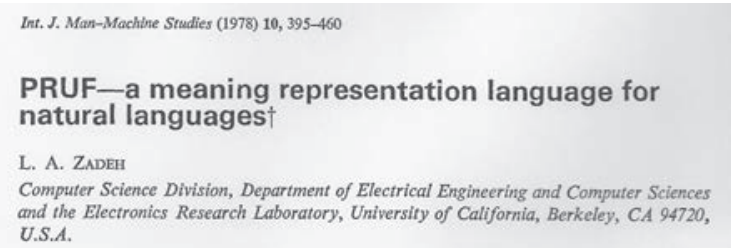
and the Electronics Research Laboratory, University of Califormia, Berkeley, CA 94720 ,
U.S.A.

Figure 21: From left above to right below: Headlines of Zadeh's articles [14,73,76,77].

It was in these 1970's when the Berkeley-psychologist Eleonor Rosch developed her prototype theory on the basis of empirical studies. This theory assumes that people perceive objects in the real world by comparing them to prototypes and then ordering them accordingly. In this way, according to Rosch, word meanings are formed from prototypical details and scenes and then incorporated into lexical contexts depending on the context or situation. It could therefore be assumed that different societies process perceptions differently depending on how they go about solving problems [78]. When the linguist George Lakoff heard about Rosch's experiments, he was working at the Center for Advanced Study in Behavioral Sciences at Stanford. During a discussion about prototype theory, someone there mentioned Zadeh's name and his idea of linking English words to membership functions and establishing fuzzy categories in this way. Lakoff and Zadeh met in 1971/72 at Stanford to discuss this idea and also the idea of idea of fuzzy logic, after which Lakoff wrote his paper "Hedges: A Study in Meaning Criteria and the Logic of Fuzzy Concepts" [79]. In this work, Lakoff employed "hedges" (meaning barriers) to categorize linguistic expressions and he invented the term "fuzzy logic" whereas Goguen had used "logic of inexact concepts" (see chapter II.1).

Based on his later research, however, Lakoff came to find that fuzzy logic was not an appropriate logic for linguistics: In my interview he said: "It doesn't work for real natural languages, in traditional computer systems it works that way." [80] But: "Inspired and influenced by many discussions with Professor G. Lakoff concerning the meaning of hedges and their interpretation in terms of fuzzy sets," Zadeh had also written an article in 1972 in which he contemplated "linguistic operators", which he called "hedges": "A Fuzzy Set-Theoretic Interpretation of Hedges".

\footnotetext{
${ }^{25}$ We quoted some paragraphs of the first part of this article [14] already in chapter 2.1

${ }^{26} \mathrm{PRUF}$ is an acronym for "Possibilistic Relational Universal Fuzzy".
} 
Here he wrote: "A basic idea suggested in this paper in that a linguistic hedge such as very, more, more or less, much, essentially, slightly etc. may be viewed as an operator which acts on the fuzzy set representing the meaning of its operand" [81].

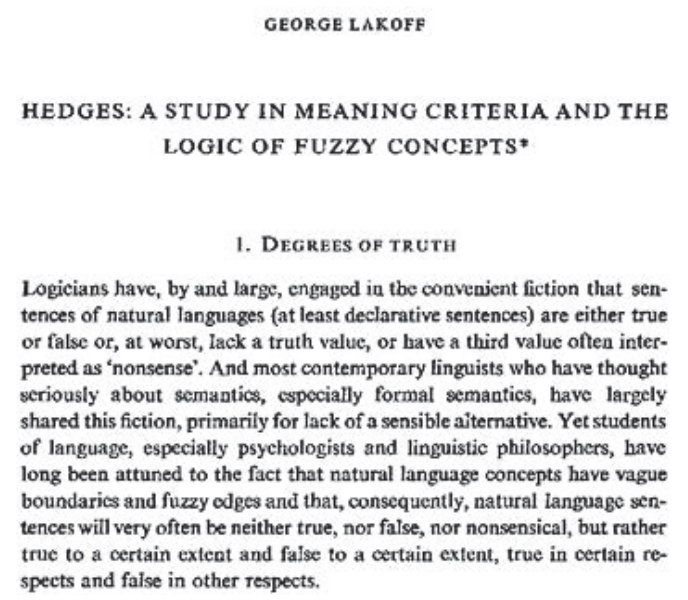

Jouras of Cylbernetios, 1972, 2, 3, pp. 4-34

A Fuzzy-Set-Theoretic Interpretation of Linguistic Hedges

L. A. Zadeh ̧̧

of Electrical Engineering and Computer Sciences

University of Califormia, Berkeley

Figure 22: Headlines of Lakoff's article [79] and Zadeh's articles [81].

\section{The "Fuzzy Boom" with Fuzzy Control - and thereafter?}

Richard Bellman left the RAND Corporation in 1965 and was appointed Professor of Mathematics, Electrical Engineering and Medicine at the University of California, Los Angeles (UCLA). ${ }^{27}$ This unusual title alone illustrates Bellman's multifaceted gifts and interests. His close friendship with Zadeh resulted in a number of co-authored publications. Bellman had been invited to deliver a lecture at the International Symposium on Multiple-Valued Logic at Indiana University in Bloomington, Indiana in May of 1975. He spoke on the subject of "Local Logics". The symposium proceedings includes only a 27-page abstract and a note indicating that the print version would be published in the book Modern Uses in Multiple-Valued Logic [82]. This 1977 tome does include the 62-page-long paper "Local and Fuzzy Logics" by Bellman and Zadeh ( [83], see Fig. 25), in which the concept of fuzzy sets is carried over to fuzzy logic. Here the authors postulate the following properties of fuzzy logic that we can now trace back to our topics in the last section:

- Truth values here are fuzzy sets of the unit interval that has denominations like "true", "very true", "not very true", "false", "more true" or "less true", etc.

- These truth values are generated by a grammar and they can be interpreted by means of semantic rules.

- Fuzzy logic is local, i.e. both the truth values and their conjunctions such as "AND", "OR" and "IF-THEN" have variable rather than fixed meanings.

- The interference rules of fuzzy logic are not exact but rather approximative.

In the 1970s Lotfi Zadeh expected that Fuzzy Sets, Fuzzy Systems, Fuzzy Logic, Approximate Reasoning, Fuzzy Algorithms, for short his Linguistic Approach "provides an approximate and

\footnotetext{
${ }^{27}$ For more biographical information on Bellman, see the IEEE History Center website: http://www.ieee.org/organizations/history/center/
} 


\section{R. E. BELLMAN* AND L. A. ZADEH ${ }^{* *}$}

\section{LOCAL AND FUZZY LOGICS}

Figure 23: Headline of Bellman's and Zadeh's article "Local and Fuzzy Logics", [83].

yet effective means of describing the behavior of systems which are too complex or too illdefined to admit of precise mathematical analysis." ( [73], p. 28) He expected that "even at its present stage of development" his new fuzzy method "can be applied rather effectively to the formulation and approximate solution of a wide variety of practical problems, particularly in such fields as economics, management science, psychology, linguistics, taxonomy, artificial intelligence, information retrieval, medicine and biology. This is particularly true of those problem areas in these fields in which fuzzy algorithms can be drawn upon to provide a means of description of ill-defined concepts, relations, and decision rules." ( [73], p. 44).

However, it was in the field of artificial intelligence and first of all it was the concept of Fuzzy Algorithms that fall on fertile ground: Ebrahim Mamdani (1942-2010, see Fig. 15), an electrical engineer in London ${ }^{28}$ had read Zadeh's "Outline of a New Approach to the Analysis of Complex Systems and Decision Processes" [73] shortly after it was published and he suggested to his doctoral student Sedrak Assilian that he devise a fuzzy algorithm to control a small model steam engine, as he mentioned in an interview that he gave me in 1998 [84] and he also pointed to Zadeh's 1973-paper in the article that he published together with Assilian after he had finished his PhD thesis: "The true antecedent of the work described here is an outstanding paper by Zadeh (1973) which lays the foundations of what we have termed linguistic synthesis ... and which had also been described by Zadeh as Approximate Reasoning (AR). In the 1973 paper Zadeh shows how vague logical statements can be used to derive inferences (also vague) from vague data. The paper suggests that this method is useful in the treatment of complex humanistic systems. However, it was realized that this method could equally be applied to "hard" systems such as industrial plant controllers. [85], p. 325."

In these times "human control experts" had to provide and understand the control commands and freshmen in this field had to learn these commands. Usually, an expert observed the sequence of processes and knew based on experience how he should intervene if necessary. If any rules governed how he should proceed, they would include linguistically vague expressions, since he would use words like "much", "little", "some", "very" and so forth. Words such as this have been identified in Zadeh's 1973-paper [73] as "linguistic terms" or "modifiers" of "linguistic variables".

Under Mamdani's supervision Assilian realized a fuzzy system under laboratory conditions, and the two designed a fuzzy algorithm to control a small steam engine by a fuzzy rule base system in a few days $[86,87]$. They controlled the system with input variables heat and throttle and output variables pressure and speed (Fig. 24) by a fuzzy rule base system.

\footnotetext{
${ }^{28}$ Ebrahim H. Mamdani was born in Tanzania in 1942. He studied electrical engineering at the College of Engineering in Poona, in British India for his first degree. He went to England in 1966 and he joined an MSc course at Queen Mary College, University of London for PhD studies.In his Ph D dissertation (1971) he studied feedback in Neutral Networks. He became professor of electrical engineering at the Queen Mary College and at Westfield College of London University and since 1995, he has been a professor of electrical engeneering at the Imperial College of Science, Technology and Medicine at the University of London. Ebrahim Mamdani passed away at January 22, 2010
} 
From Electrical Engineering and Computer Science to Fuzzy Languages and the Linguistic

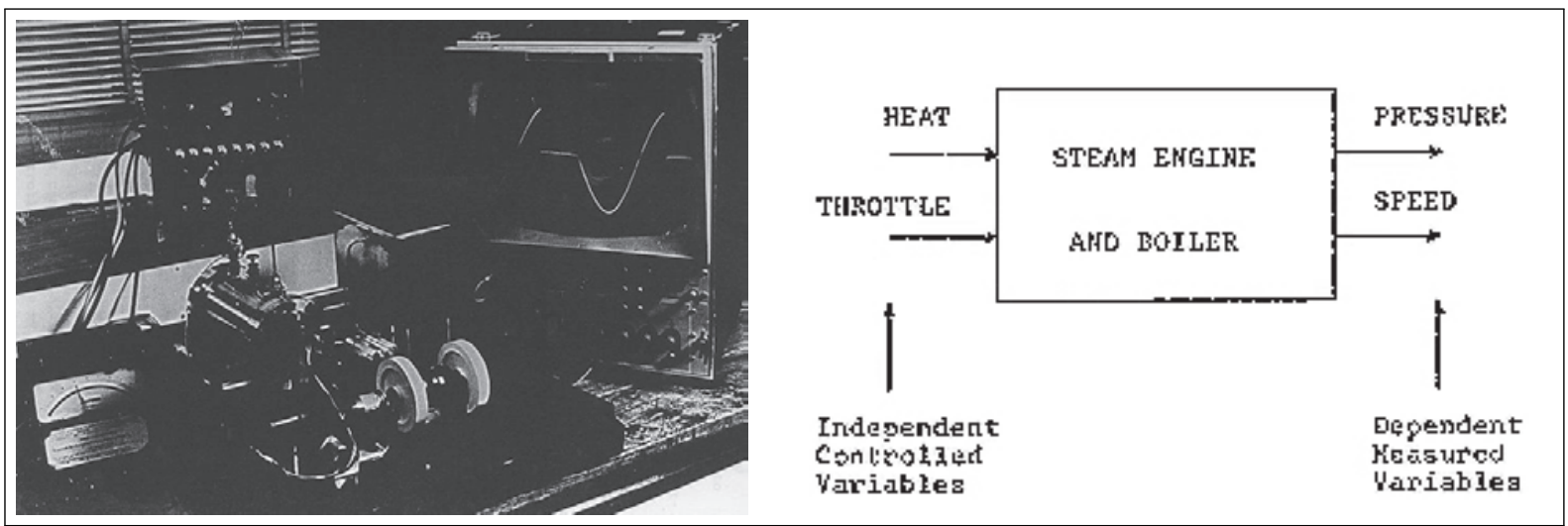

Figure 24: Photograph and schema of the real system of a steam engine [86].

Assilian published his $\mathrm{Ph}$. D. thesis on this first fuzzy control system in 1974 [86]. This steam engine heralded the Fuzzy boom that started in the 1980s in Japan and later pervaded the Western hemisphere. Many fuzzy applications, such as domestic appliances, cameras and other devices appeared in the last two decades of the 20th century. ${ }^{29}$

\section{Outlook}

In the early years of the research area of Artificial Intelligence (AI) the methods of AI were methods to compute with numbers and to find exact solutions. However, not all problems can be resolved with these methods. On the other hand, humans are able to resolve such tasks very well, as Zadeh mentioned in many speeches and articles over these decades. In conclusion, he stated that "thinking machines" do not think as humans do and from the mid-1980s he focused on "Making Computers Think like People" [16]. For this purpose, the machine's ability "to compute with numbers" was supplemented by an additional ability that was similar to human thinking.

In 1990 he began to formulate a new scientific concept when he wrote that "what might be referred to as soft computing - and, in particular, fuzzy logic - to mimic the ability of the human mind to effectively employ modes of reasoning that are approximate rather than exact. In traditional - hard - computing, the prime desiderata are precision, certainty, and rigor. By contrast, the point of departure in soft computing is the thesis that precision and certainty carry a cost and that computation, reasoning, and decision making should exploit - wherever possible - the tolerance for imprecision and uncertainty. [...] Somewhat later, neural network techniques combined with fuzzy logic began to be employed in a wide variety of consumer products, endowing such products with the capability to adapt and learn from experience. Such neurofuzzy products are likely to become ubiquitous in the years ahead. The same is likely to happen in the realms of robotics, industrial systems, and process control. It is from this perspective that the year 1990 may be viewed as a turning point in the evolution of high MIQ-products and systems. Underlying this evolution was an acceleration in the employment of soft computing - and especially fuzzy logic - in the conception and design of intelligent systems that can exploit the tolerance for imprecision and uncertainty, learn from experience, and adapt to changes in the operation conditions." [16].

At the end of the 20th century Zadeh came back to his early intention to use Fuzzy Sets and Systems and Fuzzy Logic in non-technical areas when he established the method of "Computing with Words" (CW). In 1996 he had published the article "Fuzzy Logic = Computing with Words"

\footnotetext{
${ }^{29}$ For more details on the history of Fuzzy Control and particularly the Fuzzy Steam Engine see [88] and chapter VI in the author's book [6].
} 
[69] where he proposed CW based on the theories of FSS and these methodologies instead of exact Computing with numbers $(\mathrm{CN})$. Here he wrote that "the main contribution of fuzzy logic is a methodology for computing with words. No other methodology serves this purpose" ( [89], p. 103.) and for the new millennium he published his proposal "A New Direction in AI. Toward a Computational Theory of Perceptions" [90]. Once again he clarified that this "Computational theory of perceptions" (CTP) was inspired by the remarkable human capability to operate on, and reason with, perception-based information and he assumed "that progress has been, and continues to be, slow in those areas where a methodology is needed in which the objects of computation are perceptions perceptions of time, distance, form, and other attributes of physical and mental objects." ( [90], p. 73).

Since that time, many scientists work hard to contribute with mathematical and logical thinking to establish theories in the areas of CW and CTP. This research lacks the contribution from humanities and social sciences. CW and CTP cannot arise without the fundamentals in these fields and on the other hand: they will lead to new developments in the humanities, such as in linguistics, philosophy or economics.

\section{Acknowledgments}

I would like to thank Lotfi A. Zadeh for his generous support to my work on the history of fuzzy sets and systems and its applications for more than 10 years. Especially, I would like to thank him for his offer to let me browse in his private archives in his office in Soda Hall, UC Berkeley and at his home to search and find many important and interesting materials for my historical research. Work leading to this paper was partially supported by the Foundation for the Advancement of Soft Computing Mieres, Asturias (Spain).

I would like to thank to this foundation as well as to the Scientific Committee of the European Centre for Soft Computing in Mieres, Asturias, Spain. I also thank Enric Trillas and Claudio Moraga very much for important help to write this article.

\section{Bibliography}

[1] L. A. Zadeh: Fuzzy Sets, Information and Control, 8, 1965, pp. 338-353.

[2] L. A. Zadeh, Fuzzy Sets and Systems. In: Fox, J. (ed.): System Theory, New York: Polytechnic Press 1965, pp. 29-37.

[3] L. A. Zadeh, Toward a Theory of Fuzzy Systems, Electronic Research Laboratory, University of California, Berkeley 94720, Report ERL-69-2, 6, 1969.

[4] L. A. Zadeh, Towards a theory of fuzzy systems. In: R.E. Kalman, N. DeClaris, (eds.): Aspects of Network and System Theory, New York: Holt, Rinehart and Winston, 1971, pp. 469-490.

[5] L. A. Zadeh, Interview with Lotfi Zadeh, Creator of Fuzzy Logic by Betty Blair, Azerbaijada International, winter 1994 (2.4): http://www.azer.com /aiweb/categories/magazine/24_folder/24_articles/24_fuzzylogic.html.

[6] R. Seising, The Fuzzification of Systems. The Genesis of Fuzzy Set Theory and Its Initial Applications - Developments up to the 1970s, Studies in Fuzziness and Soft Computing Vol. 216, Berlin, New York, [et al.]: Springer 2007.

[7] J. von Neumann, First Draft of a Report on the EDVAC: http://www.alt.ldv.ei.tum.de/lehre/pent/skript/VonNeumann.pdf. 
[8] W. S. McCulloch and W. H. Pitts, A Logical Calculus of the Ideas Immanent in Nervous Activity, Bulletin of Mathematical Biophysics, vol. 5, pp. 115-133, 1943.

[9] A. M. Turing, Computing Machinery and Intelligence. In: Mind, vol. LIX, 1950, pp. 433-460.

[10] C. E. Shannon, A Mathematical Theory of Communication, The Bell System Technical Journal, 27, pp. 379-423 \& 623-656, 1948.

[11] N. Wiener, Cybernetics or Control and Communications in the Animal and the Machine. Cambridge, Massachusetts, MIT Press, 1948.

[12] E. C. Berkeley, Giant Brains or Machines that Think, New York, John Wiley \& Sons, 1949.

[13] L. A. Zadeh, Thinking machines - a new field in electrical engineering, Columbia Engineering Quarterly, January 1950, pp. 12-13, 30-31.

[14] L. A. Zadeh, The Concept of a Linguistic Variable and its Application to Approximate Reasoning I, Information Science, 8, 1975, S. 199-249: 200.

[15] L. A. Zadeh, Outline of a new approach to the analysis of complex systems and decision processes, IEEE Trans. On Systems, Man, and Cybernetics, SMC-3 (1), January, 1973, pp. $28-44$.

[16] L. A. Zadeh, Making Computers Think like People, IEEE Spectrum, 8, 1984, pp. 26-32.

[17] L. A. Zadeh, The Birth and Evolution of Fuzzy Logic - A Personal Perspective, Journal of Japan Society for Fuzzy Theory and Systems, vol. 11, No. 6, 1999, pp. 891-905.

[18] L. A. Zadeh, System Theory, Columbia Engineering Quarterly, Nov. 1954, pp. 16-19, and 34.

[19] L. A. Zadeh, From Circuit Theory to System Theory, Proceedings of the IRE, Vol. 50, 1962, pp. 856-865.

[20] L. A. Zadeh, Desoer, Ch. A., Linear System Theory: The State Space Approach. New York; San Francisco, Toronto, London: McGraw-Hill Book Company 1963.

[21] L. A. Zadeh, Polak, E., System Theory, Bombay and New Delhi: McGraw-Hill 1969.

[22] L. A. Zadeh, The Concept of State in System Theory, [20], pp. 9-42.

[23] Mesarovic, M. D., Views on General Systems Theory, Proceedings of the Second Systems Symposium at Case Institute of Technology, Huntington, New York, Robert E. Krieger Publ. Comp. 1964.

[24] L. A. Zadeh, The Concept of State in System Theory. In: [23], pp. 39-50.

[25] L. A. Zadeh, Fuzzy Systems Theory: A Framework for the Analysis of Humanistic Systems. In: Roger E. Cavallo (ed.): Systems Methodology in Social Science Research: Recent Developments, Kluwer Nijhoff Publishing, Boston and The Hague. 1982 pp. 25-41.

[26] Bellman, R. E., Kalaba, R., Zadeh, L. A., Abstraction and Pattern Classification. Memorandum RM-4307-PR, Santa Monica, California: The RAND Corporation, October 1964.

[27] Zadeh, L. A., My Life and Work - a Retrospective View. Applied and Computatonal Mathematics, Vol. 10, Nr. 1, Special Issue on Fuzzy Set Theory and Applications, dedicated to the 90th birthday of Prof. Lotfi A. Zadeh, 201, pp. 4-9: 
[28] R. E. Bellman, R. Kalaba, L. A. Zadeh, Abstraction and Pattern Classification, Journal of Mathematical Analysis and Applications, 13, 1966, S. 1-7.

[29] Zadeh, L. A., Fuzzy Sets, Information and Control, 8, 1965, pp. 338-353.

[30] Zadeh, L. A., Fuzzy Sets and Systems. In: Fox, Jerome (ed.): System Theory. Microwave Research Institute Symposia Series XV, Brooklyn, New York: Polytechnic Press 1965, p. 29-37.

[31] Zadeh, L. A., Fuzzy Languages and their Relation to Human and Machine Intelligence. In: Man and Computer. Proc. Int. Conf. Bordeaux 1970, Karger: Basel, München, New York, 1970, pp. 130-165.

[32] L. A. Zadeh, Fuzzy Logic, Neural Networks, and Soft Computing, Communications of the $A C M$, vol. 37 , no. 3,1994 , pp. $77-84$.

[33] J. Goguen, Categories of Fuzzy Sets: Applications of a Non-Cantorian Set Theory. Ph.D. Thesis. University of California at Berkeley, June 1968.

[34] J. Goguen, L-Fuzzy Sets, Journal of Mathematical Analysis and Applications, 18, pp. 145$174,1967$.

[35] J. Goguen, The Logic of Inexact Concepts, Synthese, 19, pp. 325-373, 1969.

[36] L. A. Zadeh, "Biological Application of the Theory of Fuzzy Sets and Systems". In: Proctor, LD. (ed.): The Proceedings of an International Symposium on Biocybernetics of the Central Nervous System. London: Little, Brown and Comp., 1969, pp. 199-206.

[37] L. A. Zadeh, Toward a Theory of Fuzzy Systems, Electronic Research Laboratory, University of California, Berkeley 94720, Report No. ERL-69-2, June 1969.

[38] L. A. Zadeh, Towards a theory of fuzzy systems. In: R.E. Kalman, N. DeClaris, Eds., Aspects of Network and System Theory, New York: Holt, Rinehart and Winston, 1971, pp. 469-490.

[39] L. A. Zadeh, The Concept of a Linguistic Variable and its Application to Approximate Reasoning - I, Information Science 8, 1975, S. 199-249.

[40] N. Rashevsky: The logical mechanisms of logical thinking. Bulletin of Mathematical Biophysics, vol. 8, 1946.

[41] W. R. Ashby, Design for Brain. New York: Wiley, 1960.

[42] J. Pfeiffer, Thinking Machine, Philadelphia: Lippincott, 1962.

[43] M. Minsky, Matter, mind and models. Proceedings of the IFIP Congress, 1965, pp. 45-49.

[44] H. L. Dreyfus: Alchemy and artificial intelligence. Rand paper P-3244, Santa Monica: RandCorporation, 1965.

[45] Papert, S., The artificial intelligence of H. L. Dreyfus. A budget of fallacies, Memorandum 154, Project MAC, (Cambridge: MIT Press, 1968.

[46] H. L. Dreyfus, A critique of artificial reasoning. London: Harper \& Row, 1971.

[47] R. E. Bellman: Man, society and the computer, Conference Man and Computer, Bordeaux: Institute de la vie, 1970. 
[48] S. K. Chang, On the Execution of Fuzzy Programs Using Finite-State Machines, IEEE Transactions on Computers, March 1972 (vol. 21 no. 3), pp. 241-253. Or: "Fuzzy Programs - Theory and Applications", Proceedings of the Symposium on Computers and Automata, Polytechnic Institute of Brooklyn, Vol. 21, April 1971, 147-164.

[49] R. S. Interview with L. A. Zadeh on July 5, 2002, University of California, Berkeley, Soda Hall.

[50] William Go Wee and King Sun Fu, A Formulation of Fuzzy Automata and its Application as a Model of Learning Systems. In: IEEE Transactions on Systems Science and Cybernetics. Vol. SSC-5, No. 3, pp. 215-223, 1969.

[51] William Go Wee, On a Generalization of Adaptive Algorithms and Applications of the Fuzzy Set Concept to Pattern Classification. Ph.D. Thesis, Purdue University, Technical Report, $67,7,1967$.

[52] Chin-Liang Chang, Fuzzy Sets and Pattern Recognition. Ph.D. Thesis. Department of Electrical Engineering, University of California, Berkeley, December 1967.

[53] L. A. Zadeh, Fuzzy Algorithms. In: Information and Control, vol. 12, pp. 99-102, February 1968 .

[54] R. Seising: Interview with L. A. Zadeh (19.6. 2001), University of California, Berkeley, Soda Hall (unpublished).

[55] L. A. Zadeh, Toward Fuzziness in Computer Systems. Fuzzy Algorithms and Languages. (Script, without date and publisher)

[56] P. Turakainen, On Stochastic Languages, Information and Control, vol. 12, April 1968, pp. 304-313.

[57] E T. Lee and L. A. Zadeh, Note on Fuzzy Languages, Information Sciences, vol. 1, 1969, pp. 421-434.

[58] J. E. Hopcroft and J. D. Ullman, Formal Languages and their Relation to Automata. Reading, Mass.: Addison Wesley, 1969.

[59] L. A. Zadeh, Similarity Relations and Fuzzy Orderings. In: Information Sciences, vol. 3, pp. 177-200, 1971.

[60] L. A. Zadeh: Quantitative Fuzzy Semantics. In: Information Sciences, vol. 3, pp. 159-176, 1971.

[61] S. Abraham and S. Kiefer, A Theory of Structural Semantics, The Hague: Mouton, 1965.

[62] Y. Bar-Hillel, Language and Information, Reading, Mass.: Addison-Wesley, 1964.

[63] M. Black, The Labyrinth of Language, New York: Mentor Books, 1968.

[64] R. Carnap, Meaning and Necessity, Chicago: University of Chicago Press, 1956.

[65] N. Chomsky, Cartesian Linguistics, New ok: Harper \& Row, 1966.

[66] J. A. Fodor and J. J. Katz, The Structure of Language, Englewood Cliffs, N. J.: PrenticeHall, 1964. 
[67] L. Linsky, Semantics and the Philosophy of Language, Urbana, Ill.: University of Illinois Press, 1952.

[68] J. Lyons, Introduction to Theoretical Linguistics, Cambridge: Cambridge University Press, 1968.

[69] S. Ullmann, Semantics: An Introduction to the Science of Meaning. Oxford: Blackwell, 1962.

[70] W. Van Orman Quine, Word and Object, Cambridge: MIT Press, 1960.

[71] S.K. Shaumyan, Structural Linguistics, Moscow: Nauka, 1967.

[72] Z. Harris, Mathematical Structures of Language, New York: Interscience, 1968.

[73] L. A. Zadeh, Outline of a new approach to the analysis of complex systems and decision processes, IEEE Trans. On Systems, Man, and Cybernetics, SMC-3 (1), January, 1973, pp. $28-44$.

[74] L. A. Zadeh, The Concept of a Linguistic Variable and its Application to Approximate Reasoning II, Information Science, 8, 1975, S. 301-357.

[75] L. A. Zadeh, The Concept of a Linguistic Variable and its Application to Approximate Reasoning III, Information Science, 9, 1975, S. 43-80.

[76] L. A. Zadeh, Fuzzy Logic and Approximate Reasoning, Synthese, vol. 30, 1975, pp. 407-428.

[77] L. A. Zadeh, PRUF - a meaning representation language for natural languages, International Journal of Man-Machine Studies, vol. 10, 1978, pp. 395-460.

[78] E. Rosch, Natural Categories, Cognitive Psychology, 4, pp. 328-350, 1973.

[79] G. Lakoff Hedges, A Study in Meaning Criteria and the Logic of Fuzzy Concepts, Journal of Philosophical Logic, 2, pp. 458-508, 1973.

[80] R. Seising, Interview with George Lakoff (6.8. 2002), University of California, Berkeley, (unpublished).

[81] L.A. Zadeh, A Fuzzy-Set-Theoretic Interpretation of Linguistic Hedges, Journal of Cybernetics, vol. 2, pp. 4-34, 1972.

[82] R. E. Bellman, Local Logics. In: IEEE Logic, p. 175, 1975.

[83] R. E. Bellman, and L. A. Zadeh, Local and Fuzzy Logics. In: M. J. Dunn and G. Epstein (eds.): Modern Uses of Multiple-Valued Logic. In: Invited Papers from the Fifth International Symposium on Multiple-Valued Logic. Held at Indiana University, Bloomington, Indiana, May 13-16, 1975. Dordrecht, Boston: D. Reidel, 1977, pp. 105-165, 1977.

[84] R. S. Interview with E. Mamdani $(9.9,1998)$, Aachen, RWTH Aachen, at the margin of the European Congress on Intelligent Techniques and Soft Computing EUFIT 1998.

[85] E. H. Mamdani, Advances in the Linguistic Synthesis of Fuzzy Controllers, International Journal of Man-Machine Studies, vol. 8, pp. 669-678, 1976.

[86] Assilian, A., Artificial Intelligence in the Control of Real Dynamic Systems. Ph. D. Thesis DX193553, University London, August 1974. 
From Electrical Engineering and Computer Science to Fuzzy Languages and the Linguistic

[87] E. H. Mamdani and S. Assilian, An experiment in linguistic synthesis with a fuzzy logic controller, International Journal of Man-Machine Studies, 7 (1), 1975, pp. 1-13.

[88] R. Seising, The Experimenter and the Theoretician - Linguistic Synthesis to tell Machines what to do. In: Enric Trillas, Piero Bonissone, Luis Magdalena, Janusz Kacprycz (eds.): Experimentation and Theory - Homage to Abe Mamdani, Physica-Verlag Series 'Studies in Fuzziness and Soft Computing', 2011 (to appear).

[89] L.A. Zadeh, Fuzzy Logic = Computing with Words, IEEE Transactions on Fuzzy Systems, vol. 4, no. 2, 1996, pp. 103-111.

[90] L.A. Zadeh, A New Direction in AI. Toward a Computational Theory of Perceptions, AIMagazine, vol. 22, no. 1, 2001, pp. 73-84. 